\title{
A multidimensional continuum model of fish population dynamics and behaviour: Application to the Barents Sea capelin (Mallotus Villosus)
}

\author{
MARK REED $\ddagger$ and JENS G. BALCHEN§
}

Keywords: capelin, fishery dynamics, fish populations, population dynamics, ecosystem modeling, fish migration, fish behaviour, behaviour modeling.

The theoretical basis for a fishery model continuous in physical, temporal, and biological dimensions is discussed. A concrete application, constructed as one component of a larger system of physical and biological dynamic models descriptive of the Barents Sea ecosystem, is presented. Some of the potentials of such an approach are demonstrated through an example simulation of population dynamics. Simple parameterizations of other components of the ecosystem (ocean currents, temperature, sea ice, cod, marine mammals, the fishing fleet, copepods, and krill) are used to provide an ersatz environment in which to perform simulation tests.

\section{Introduction}

The fish population model described here has been constructed as one component of a larger system of models of the Barents Sea ecosystem (Balchen 1980). The central formulations therefore assume the existence of a dynamically simulated environment (hydrodynamics, temperature, salinity, light, sea ice, plankton, predators), as well as physiological and behavioural submodels. Because these other system components are under simultaneous development (Slagstad 1980; Ebenhöh 1980; Berntsen et al. 1981; Balchen 1979), low-order simplified deterministic formulations have been constructed to supply inputs for operational testing purposes. These model sections and formulations have been denoted by an asterisk (*) to identify their transitive nature. Although actualization of the model in computer code has been restricted by present realities of machine speed and capacity, the theoretical foundations are formulated with the expectation that future computer evolution will greatly reduce these limitations.

Proposed here is a general approach to the modeling of fish population dynamics, one which is completely continuous, not only in the dimensions of time and space, but also in whatever biological properties may be of interest, such as age, length, weight, or even genetic configurations. This approach allows for the orderly implementation of dynamic formulations of the underlying processes which have traditionally been represented by parameterizations, and the initiation of population model formulation in a manner which theoretically includes every possible 'state of being' as a specific point in a multidimensional state, or property, space. By selecting

Received 6 January 1982

† Applied Science Associates, Inc., Wakefield, Rhode Island, U.S.A.

$\ddagger$ This work was done during the author's stay at The Norwegian Institute of Technology, Division of Engineering Cybernetics, Trondheim, Norway.

$\S$ University of Trondheim, The Norwegian Institute of Technology, Division of Engineering Cybernetics, Trondheim, Norway.

M.I.C. 
those characteristics of the population which are of greatest interest, one can proceed from this general theoretical vantage point to a feasible numerical realization of the model. If one also attempts to model important processes as dynamic events, rather than representing them as 'average values', and combines such process-oriented modeling with a Kalman filter-type updating system (Balchen 1979), many of the shortcomings of earlier highly parameterized formulations can be overcome.

\section{Overview of a specific application of the continuous property space approach}

\subsection{Biological and ecological summary of capelin in the Barents Sea}

The capelin is a boreal pelagic plankton feeder and migratory spawner. Mature adults are typically 14 to $18 \mathrm{~cm}$ in length. Like other plankton feeders, the capelin is a schooling fish, an attribute which may serve some protective function for the individual, possibly lends a hydrodynamic, energy saving advantage (Weihs 1973), and is probably also a necessity imposed by the patchy nature of the food supply (see section 3.4 (d)). Capelin in the Barents Sea spawn off the coast of Finnmark (Fig. 1) in early spring in water of approximately $2^{\circ}-4^{\circ} \mathrm{C}$ and 25 to $150 \mathrm{~m}$ in depth (Sætre and Gjøsætre 1975). Spawning stocks consist primarily of 3 and 4 year old fish, although the mean age, as well as timing and location of spawning, are rather variable from year to year (e.g. Prokhorov 1968; Olsen 1968; Møller and Olsen 1962). Eggs are deposited on a gravel substrate to which they adhere by a saltwater-activated glue (Friogeirsson 1976), an attribute perhaps evolved because (a) the optimal location for hatching is fairly specific, due to larval food and transport considerations, or $(b)$ the parent stock is precluded from successfully spawning further downstream due to excessive temperatures, migration energy costs, or potential predation on themselves or their young. Spawning stock mortality appears to be extremely high, the major causes being physical dissipation (Jangaard 1974), abrasive wounds received during the spawning act (Friðgeirsson, 1976), and heavy predation by cod (e.g. Anon. 1975; Ponomorenko and Yaragina 1978), marine mammals (Bergfløt and Christensen personal communications), and man, as reflected in recent yields during the spring of about 1 million tons.

Incubation of eggs, which are $1 \cdot 1-1 \cdot 2 \mathrm{~mm}$ in diameter (Gjøsæter and Monstad 1973), takes about 55 days at $0^{\circ} \mathrm{C}$, minus about 5 days per degree increase (Jeffers 1931). Newly hatched larvae range from 3 to $8 \mathrm{~mm}$ in length.

The larval yolk sac is resorbed in 8 to 10 days under starvation conditions, but at a lesser rate if the larvae find food during this time. Copepod eggs and nauplii constitute over $90 \%$ of the diet (Bjørke 1976). Feeding appears to occur exclusively during daylight hours, a consideration which is non-limiting in the Barents Sea from June to August. Capelin larvae are located in the top few meters of the water column, and demonstrate increasing vertical and horizontal swimming activity as they grow longer (Beltestad, Nakken, and Smedstad 1975).

The Barents Sea capelin are 5-9 cm long at the end of their first winter, and $14-19 \mathrm{~cm}$ in length at age 3 , when most mature (e.g. Anon. 1975). Adults feed primarily in the north during the summer months, but move progressively south with the advent of winter and the southward movement of sea ice (Fig. 1).

As plankton feeders, capelin occupy an important position in the ecosystem, facilitating the transfer of energy from primary and secondary production to higher trophic levels. Cod, whales, and seals are their major natural predators in the Barents Sea. One estimate places the annual consumption by cod at 6 million tons per year 


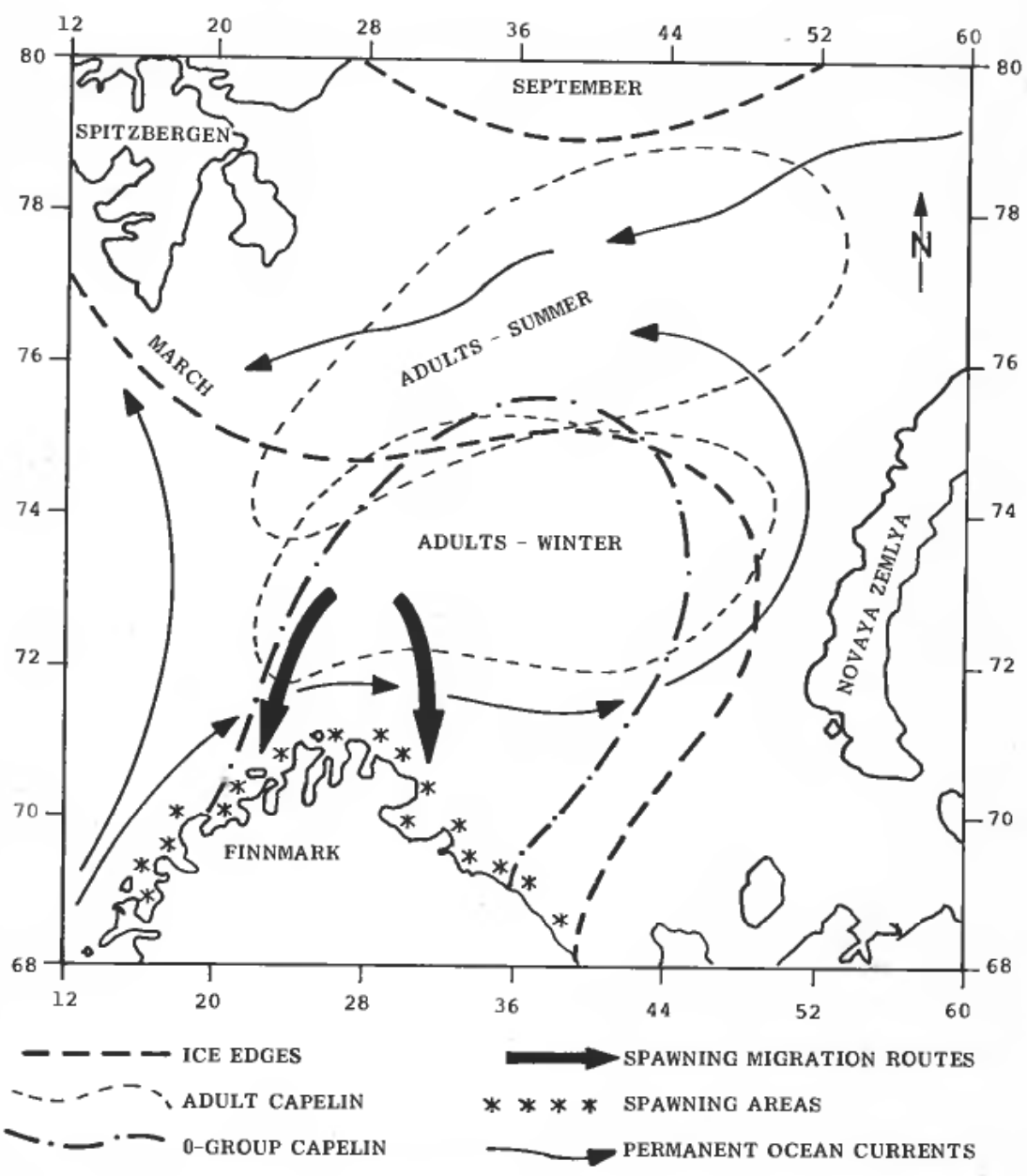

Figure 1. Map of the Barents Sea area, showing approximate mean locations of ice edges in early spring and late summer, primary ocean currents distributions of adult capelin in summer and winter, and the 0-group in autumn, spawning areas, and migration routes (after Loeng 1979; Novitskiy 1961; Anon. 1958, 1973-1981).

(Ponomorenko et al. 1978), and the consumption by marine mammals may be about the same order of magnitude (Christensen personal communication). In addition, the international (primarily Norwegian and Russian) fishery currently takes 1 to 3 million tons per year. Acoustic surveys indicate a total stock size of about 6 million tons (Nakken and Dommasnes 1977), belying the accuracy of some of the predation estimates. It is at any rate part of the purpose of a model such as this to assist in achieving a consistent understanding of the ecosystem.

\subsection{Selection of continuum dimensions}

The dimensions of the model property space have been selected on the assumption that correct representations of physical and biological distributions require the modeling of behaviour and physiology. In other words, the fish are where they are and do what they do (grow, eat, swim, spawn) because of their instantaneous physiological states. A fish does not 'decide' when to do these things. It is a complex, preprogrammed biochemical system whose behaviour at any given time is determined 
by its external physiochemical environment and internal physiological state. The model must therefore incorporate representations of these properties, which are important in determining behavioural responses.

The model should also be useful in the testing of specific hypotheses concerning factors underlying events and processes of interest in the management of the fishery:

(1) annual variations in spawning migration routes and spawning areas;

(2) timing and number of spawning migrations each year;

(3) growth patterns of individuals, and of the population as a whole;

(4) egg and larval survival, and therefore recruitment;

(5) population response to variations in fishing pressure;

(6) importance of predation by animals other than man, as well as abiotic factors, in determining population dynamics.

In addition to the usual properties of interest in fisheries management (age, length, weight), allowance has been made for the inclusion of the physiological properties of satiation level, condition factor, and both reversible and irreversible protein and lipid storages. Of the first three, only age and length are explicit since length and weight are uniquely related through the condition factor. Because mature and immature females appear to grow and behave differently, and to suffer different mortality rates (e.g. Jangaard 1974; Monstad 1971; Friðgeirsson 1976), the dimensions of sex and sexual maturation stage have also been incorporated.

\subsection{Elementary model reduction}

It should be stressed that all properties, or dimensions, included in the theoretical formulation are in theory continuously distributed variables, although some locations in the total state space may be virtually empty. The sex of an egg, for example, can be considered halfway between male and female, having approximately equal (or perhaps slightly biased) potential for development in either direction. The male of a species also carries female characteristics. Although these are generally subliminal, reversal of sex has been observed in a variety of animals, and can be artificially induced to full fertility in salmonids (Johnstone et al. 1977).

The introduction of discontinuous variables (e.g. male and female fish) is nonetheless a convenience which eliminates the need to store or perform numerical calculations in essentially empty property space, without neglecting effects of known importance. The development of a fish from egg to mature adult is of course a continuous process, but the model discussed here is based on formulations in which eggs, larvae, and adults are modeled separately, with developmental transfer linkages between domains. It is unnecessary to represent eggs and larval fish in either sex or sexual maturity dimensions, and the introduction of transformations parallel to the time and length axes is facilitated, accommodating higher resolution in the numerical discretization schemes at larval stages, and temperature dependent hatching rates for eggs. In addition, it becomes relatively simple to incorporate embedded timesteps to meet numerical stability restrictions in the faster changing model regions, such as larval growth, without limiting the timestep in regions characterized by slower changes, such as adult growth and advective transport, thus decreasing overall computational time. 
For computational manageability, the model is only quasi-three dimensional in physical space, in that location of fish in the vertical can be assigned a characteristic time-varying value at any location in the horizontal.

Future experience with model operation will permit further reduction of storage allocation and program run time. For example, all male fish in a given physiological state (specific values of satiation level, condition factor, and protein and lipid storages) and at a given physical location in the simulated ocean, are also located somewhere within an age-length-sexual maturity space (Fig. 2). Clearly, very young fish of very great length or high sexual maturity state will be rare or non-existent. The introduction of reasonable maximum and minimum growth parameters leads to a reduction in the 'active property space', such as is indicated by the shaded region in Fig. 2. With the completion of the physiological model and subsequent determination of realistic growth limits, reductions of this type will be applied.

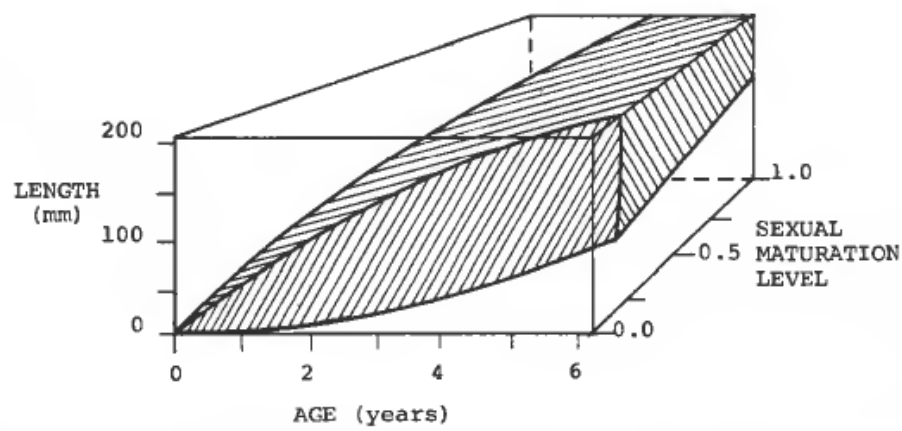

Figure 2. Schematic length-age-sexual maturity property space for the Barents Sea capelin. The shaded region suggests the 'active' volume, within which most of the population will always be found.

\section{Endogenous model details}

This section presents the mathematical formulations representing various aspects of the capelin population dynamics. To clarify the discussion, the physical discretization is presented first.

\subsection{Physical domain}

The discretized grid system in horizontal space is shown in Fig. 3. Transport velocity components $u$ and $v$, positive in the $x$ (easterly) and $y$ (northerly) directions respectively, are assigned at the midpoints of grid sides, whereas transported constituents such as temperature, capelin, and zooplankton concentrations, are defined at grid centres. Figure 3 also shows the location of spawning areas, subject to limitations of resolution. Specific grid cells are referred to in the text by row number $(I)$, and column number $(J)$, the first spawning grid at the lower left therefore being $(3,1)$. Details of the simulated physical environment are given in $\S 4.1$.

\subsection{Eggs}

An example model distribution of eggs at spawning site $(4,5)$ during March is shown in Fig. 4. A mature female's length $L(\mathrm{~cm})$ is related to $E$, the number of eggs she will spawn, by the equation (Gjøsæter and Monstad 1973)

$$
E=0.624 L^{3.49}
$$


The distribution of egg size is as important in the model as egg number, since it is assumed that larger eggs produce larger larvae (or equivalently larvae with larger yolk sacs), which then can last longer and grow longer before first feeding becomes imperative for survival (Blaxter and Hempel 1963; Gall 1974; Blaxter 1969 a). Privolnev, Galkina, and Galkin (1964) found that young obtained from larger salmon females

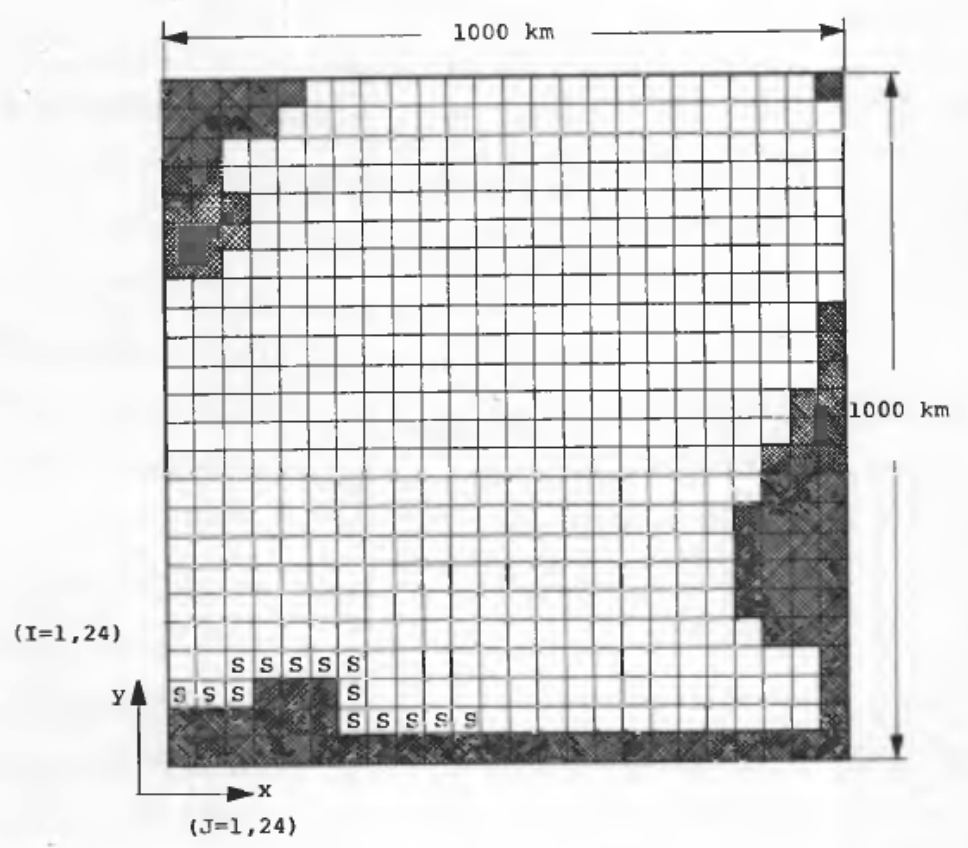

Figure 3. The finite difference grid system, showing row $(I)$ and column $(J)$ numbers to locate grids in the text, model spawning sites $(S)$, and the $x$ (east) and $y$ (north) directions, corresponding to velocity components $u$ and $v$ respectively. One grid cell is approximately $42 \mathrm{~km}$ per side.

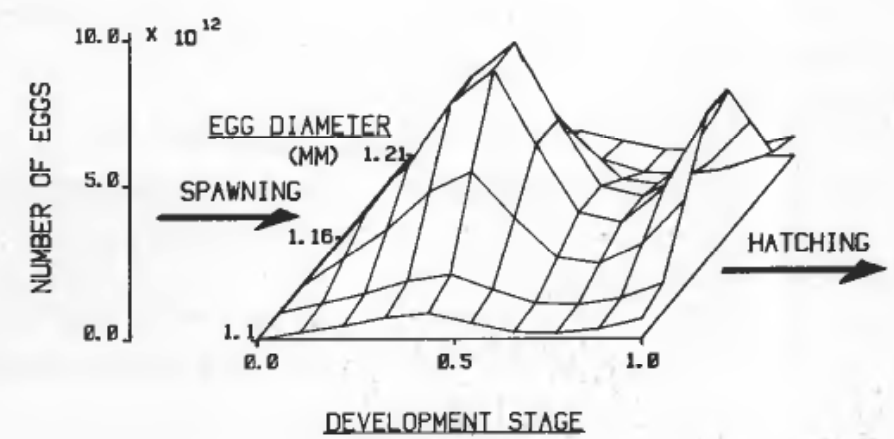

Figure 4. Example discretized egg development space in grid cell $(4,5)$ on April 20 of a simulation. The integral over the space gives the sum of eggs present in the grid cell at that time, or about $1 \times 10^{4}$ per $\mathrm{m}^{2}$ averaged over the area, corresponding to low values observed by Sætre and Gjøsæter (1975). Peaks along the development axis can result from pulsed fluxes of spawners into the area, or the passage of a cold front that slows development. 
simply had faster growth rates, which in the present model would also produce improved survival probabilities. The same authors also report that eggs produced by the largest females tended to be smaller than those produced by females of average size, as would be expected if a disproportionate amount of energy is diverted to growth rather than egg production. This type of relationship can only be properly modeled with a more complex adult physiological model than the simple parameterization used here. Parent length alone is clearly an insufficient predictor of egg size (Gjøsæter and Monstad 1963), but a combined consideration of length, age, condition factor, and number of previous spawnings may prove satisfactory. Since these factors are or can be included in the model, updating hinges only on data availability. For the present, females are assumed to produce eggs with diameters distributed normally with a mean of $1.16 \mathrm{~mm}$ and standard deviation of 0.03 , representing a qualitative synthesis of information from Friogeirsson (1976) and Gjøsæter and Monstad (1973).

For water temperatures typically observed during the spring off the coast of Finnmark $\left(0^{\circ}-7^{\circ} \mathrm{C}\right)$ hatching time $\left(T_{H}\right)$ appears acceptably approximated by

$$
T_{H}=55 \cdot 0-5 \cdot 0 T
$$

(Jangaard 1974) for $T_{H}$ in days, and $T$ in degrees Celsius.

In general the eggs are demersal and not subject to advection, although Bakke and Bjørke (1973) estimated a loss of eggs due to drift at one spawning site to be 5-10\% over a four week period. Because temperature is a function of both time and physical location, an egg fixed in physical space or transported experiences a time-varying hatching rate along the dimensionless development axis (Fig. 4), the instantaneous value used here being $1 / T_{H}$. Egg size is assumed constant during the hatching process. If the possibility of egg drift is included, the governing equation in the egg domain becomes

$$
\frac{\partial E}{\partial t}+u \frac{\partial E}{\partial x}+v \frac{\partial E}{\partial y}+\frac{1}{T_{H}} \frac{\partial E}{\partial_{H}}=S_{E}-M_{E}
$$

This is the differential form of a typical conservation equation for a continuum (e.g. Himmelblau and Bishoff 1968), and can alternatively be considered as a distribution function for eggs $E$ in their property space (e.g. Slagstad 1980). In eqn. (1) $S_{E}$ represents the instantaneous local deposition rate of eggs (spawning), and $M_{E}$ is the instantaneous sum of all mortality rates plus hatching. Drift of eggs is not a mortality source per se, but may result in larvae hatching out in areas with food supplies insufficient for survival.

Egg mortality can be attributed to a variety of potential factors such as bacterial or viral infection, predation, exposure to extremes of temperature, salinity, or toxic pollutants, mechanical damage, fertilization failure, or biochemical failure at the subcellular level (e.g. genetic abnormalities). Fertilization success appears to be nearly $100 \%$, both in the laboratory and on the spawning grounds (Sætre and Gjøsæter 1975). Predation on eggs by eider ducks and haddock has been observed, but is probably of minor significance (Ibid.). Eggs taken from spawning grounds and developed in the laboratory showed mortalities ranging from 0.0 to $10.2 \%$, the highest values being associated with disturbances by fishing trawl doors (Dragesund, Gjøsæter, and Monstad 1973; Bakke and Bjørke 1973). Information on other sources of mortality of capelin eggs has not been found.

Classical theory (e.g. Hjort 1914; Marr 1955), observations in the field and laboratory (e.g. Daan 1979, Gulland 1964), and modeling efforts (Jones 1979; Reed, 
Spaulding and Cornillon 1980) support the expectation that the period of critical mortality lies between hatching and the end of the first year of life for most fish species. Whereas eggs tend to be robust, survival of the early larval stages appears highly dependent on the availability of sufficient food of appropriate size. A female capelin of $16 \mathrm{~cm}$ in length will produce some 10000 eggs at spawning, and under conditions of heavy adult mortality perhaps 10 or 20 must reach one year of age to maintain the population size. The observations noted in the previous paragraph suggest that egg mortality is in general between $5 \%$ and $20 \%$. If total first year mortality is $99.9 \%$, and the relation between egg production and recruitment is nonlinear (as it must be for population stability) then the selection of this value is probably non-critical. A constant value of 0.005 per day, or about $20 \%$ mortality over a 45 day $\left(2^{\circ} \mathrm{C}\right)$ hatching time has been used here, subject to future sensitivity and data analysis.

Potential spawning sites have been selected according to Norwegian winter and spring survey literature (e.g. Hamre and Monstad 1980, 1979; Hamre and Sætre 1976; Sætre and Gjøsæter 1975; Dragesund, Gjøsæter and Monstand 1973). The general spawning area is indicated in Fig. 1. The actual location and timing of egg deposition varies, depending upon the migration routes and physiological state of the spawning stock in a given year of a simulation.

\subsection{Larvae}

\section{(a) Introduction}

A 3-dimensional perspective representation of a distribution of larval capelin in age-length space within one grid cell of the simulated ocean is shown in Fig. 5. At hatching Barents Sea capelin larvae are 3 to $8 \mathrm{~mm}$ in length, increasing to 2 to $7 \mathrm{~cm}$ by the end of their first summer (Dragesund 1970). Egg size is assumed positively correlated with larval length at hatching.

The relation

$$
l=20 \cdot 6 d^{3}-26 \cdot 7
$$

seems to fit the available information on Barents Sea capelin (Gjøsæter and Monstad 1973; Bjørke 1976; Prokhorov 1965), for larval length at hatching, $l$, and egg

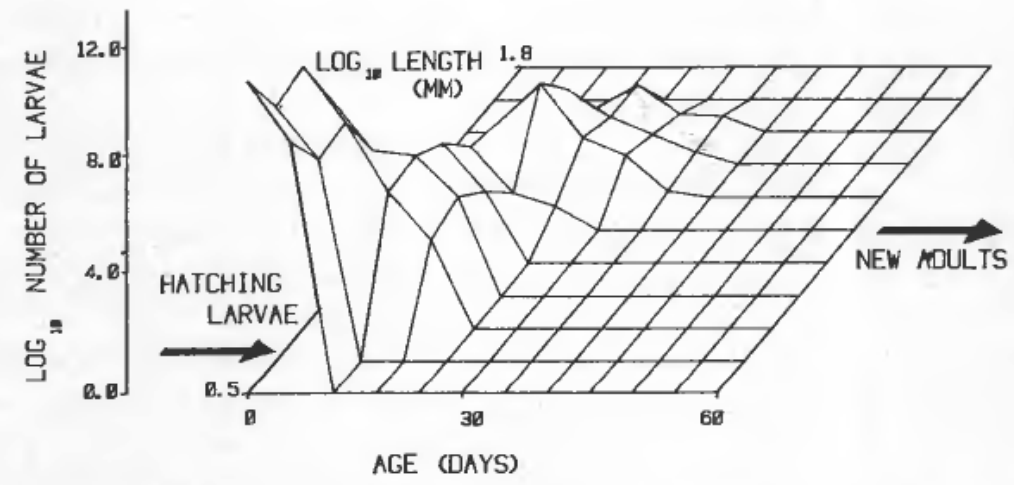

Figure 5. Example discretized larval age-length space in grid cell $(4,5)$ on May 10 of a simulation. The length dimension is logarithmic to resolve growth dynamics at the earliest stages without expending unnecessary computational storage space. Losses from the space occur as a result of starvation mortality, advection into neighbouring physical grid cells, and graduation into the adult domain. 
diameter, $d$, in $\mathrm{mm}$. The cubic (volumetric) relation is used because the larvae are curled inside the egg before hatching, and yolk size at hatching probably is correlated with increased time to death from starvation in the absence of food. Since larval survival probability is length-determined in this model, any yolk sac size advantage is translated into a length advantage via eqn. (2).

The dynamics of classes of larvae, a class being defined as all those individuals within a certain length, age, and physical space interval, are structured after previous larval modeling work (Beyer and Laurence 1979; Jones 1979; Jones and Hall 1973; Blaxter 1969, 1971).

The larvae are assigned perceptual range which increases linearly with length, whereas swimming speed, feeding and digestive efficiency increase non-linearly towards asymptotic values. The model ocean contains a copepod population undergoing its own physical and biological dynamics. The size range of prey available to a given class of larvae depends on simple mouth size and energy cost considerations. Food intake is limited by gut size and digestion rate. Growth results from energy intake over and above that needed for basic maintenance and swimming. The patchy character of zooplankton and larval distributions on scales smaller than the physical grid size has been temporarily neglected here, but will eventually be governed by another model in the system (Ebenhöh 1980). The starvation 'point of no return' death barrier suggested by Blaxter and Hempel (1963) and used by Beyer and Laurence (1979) is also incorporated.

\section{(b) Larval feeding, growth, and mortality}

If $\alpha$ is the cost of food processing, as a fraction of the food taken in, $\beta$ is a lengthdependent measure of digestion efficiency (Fig. 6), $R$ is a measure of the instantaneous ration, and $n$ and $m$ are the coefficient and exponent of metabolic costs, the differential growth equation in terms of weight $w$ is

$$
\frac{d w}{d t}=[1 \cdot 0-\alpha] \beta R-n w^{m}
$$

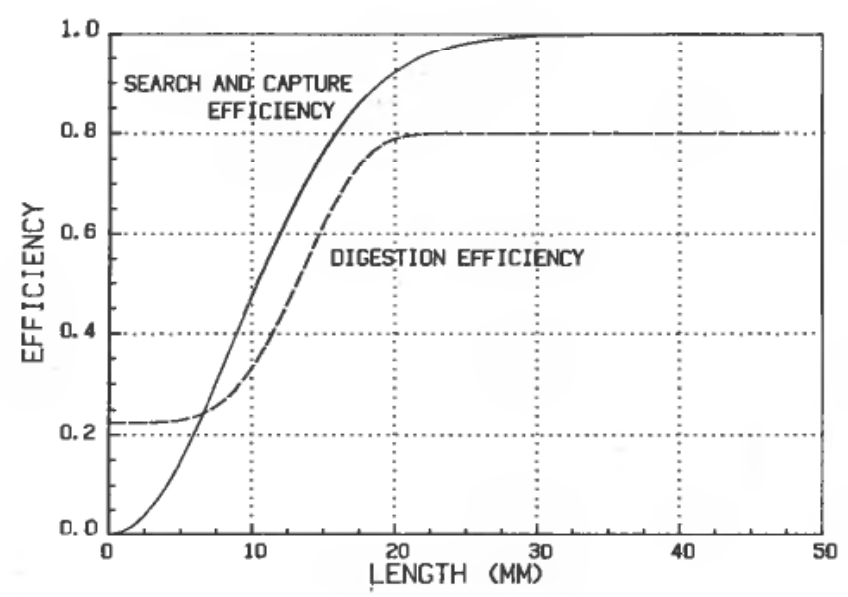

Figure 6. Graphic representations of larval search and capture, and digestion efficiency parameterizations. 
(Beyer and Laurence 1979). Larval length and weight during the first 60 days are assumed suitably related by an equation of the form

$$
w=b l^{c},
$$

so eqn. (3) has the same general form as that introduced by von Bertalanffy (1938).

Following Jones and Hall (1973), Jones (1979), and Beyer and Laurence (1979), we use a swimming speed $s$ of $1 \cdot 0$ body length per second. Although higher speeds are perhaps sustainable without the accumulation of an oxygen deficit (Blaxter $1969 \mathrm{~b}$ ), the value of unity combined with the following perceptual formulation gives results comparable to those reported by Blaxter and Staines (1971).

The perceptual field of an individual larva appears to be approximately equal to the body length (Blaxter 1969), so that for a conical field of vision (Beyer and Laurence 1979), the maximum expected volumetric searching ability $V$ in length units cubed per second becomes

$$
V=\frac{2}{3} \pi l^{3} .
$$

A larvae in a dense patch of food will of course not need to search this entire volume, but will search only that fraction necessary to capture its maximum ration, as discussed below.

The upper size limit on zooplankton available to larvae of a given length is dictated by mouth size in the model. Blaxter (1969) reports that an elastic ligament at the articulation allows even larger organisms to be taken, so that this approximation is somewhat conservative. As prey size decreases, the energy cost of capture and digestion at some point exceeds the benefit in terms of maintenance and growth. Treating the zooplankton as spherical particles of density $1 \cdot 1 \mathrm{mg} / \mathrm{mm}^{3}$, and using a larval length to mouth diameter ratio of 0.05 (estimated from Blaxter 1969), the minimum prey weight $w_{z, \min }$ obtained by balancing the estimated energy cost of capture against the growth term in eqn. (3) is given by

$$
w_{z, \min }=\frac{h}{(1-\alpha) \beta(l)} w^{m}
$$

This is eqn. (38) in Beyer and Laurence (1979), and their estimate of $h=4 \cdot 86 \cdot 10^{-6}$ (mg dry $\mathrm{wt}^{(1-m)}$ ) has also been used here. The lower and upper limits implied by these considerations are shown in Fig. 7.

Using a digestion time of 9 hours at $7^{\circ} \mathrm{C}$ (Blaxter 1969 a) and the fact that Barents Sea capelin spawn almost exclusively to the north of $69^{\circ} \mathrm{N}$ latitude, so that larvae hatching out in May can theoretically feed 24 hours per day, to modify the approximation used by Beyer and Laurence (1979), gives the maximal ration

$$
R_{\max }=0.08 l^{3},
$$

or about $5 \%$ of body weight per day.

The range of zooplankton sizes available to the larvae in the model ocean is shown in Fig. 15. Given the food size distribution and density experienced by larvae, these formulations can be used to estimate the ration consumed, the growth increment, and the reduction in zooplankton density. 


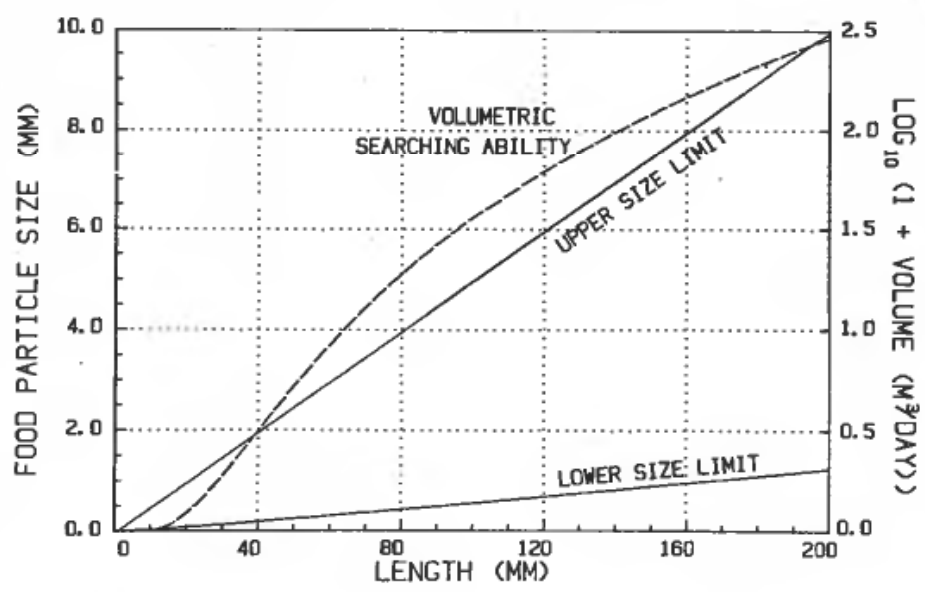

Figure 7. Feeding restriction curves as functions of length. The upper size limit is related to mouth size, and the lower to body weight.

Larval survival is modeled as a function of food intake, and therefore growth rates, as supported by Blaxter and Hempel (1963). A starvation level specifying a minimum length (or equivalently weight) is set according to

$$
l_{\min }=l_{0} \exp (a t)
$$

in which $l_{0}$ is minimum length at hatching ( $\mathrm{mm}$ ), and $t$ is age (days). Using informamation from Bjørke (1976), and minimum observed lengths for 0-group capelin (Dragesund 1970) we estimate $a=0.01$ per day, close to the value of 0.008 used by Beyer and Laurence (1979) for herring larvae. Since zooplankton densities are reduced by larval predation, it is possible even for quite large larvae to find themselves with insufficient food resources. Reduction to the minimum length barrier is an unrealistic approximation in such cases, but the incorporation of a second barrier at $60 \%$ or $70 \%$ of the maximum achieved growth (Ehrlich et al. 1976) requires machine storage of the age-length distributions for several prior timesteps, and considerable time for back-calculating growth histories, so this second limitation has not been included in the present work.

The behaviour of the set of formulations described above is shown in Fig. 8 for various densities of zooplankton. When the larvae first hatch, only the youngest stages of copepods (eggs and nauplii) are small enough to serve as food supplies. Bjørke (1976) investigated the gut contents of young capelin larvae off the coast of Finnmark, and found that the eggs and nauplii of the copepod Calanus finmarchicus constituted respectively $52 \%$ and $42 \%$ of the diet. Although the eggs were approximately half as abundant in the plankton as the nauplii, their dominance in the diet suggest that prey behaviour should perhaps be considered in calculating larval feeding success. Non-swimming eggs will certainly be easier to catch than self-motile nauplii, a consideration presently omitted here.

\section{(c) Transport}

With the inclusion of physical advection, the simulation of larval fish $(L)$ distributions in dimensions of horizontal physical space, length, and age is calculated 


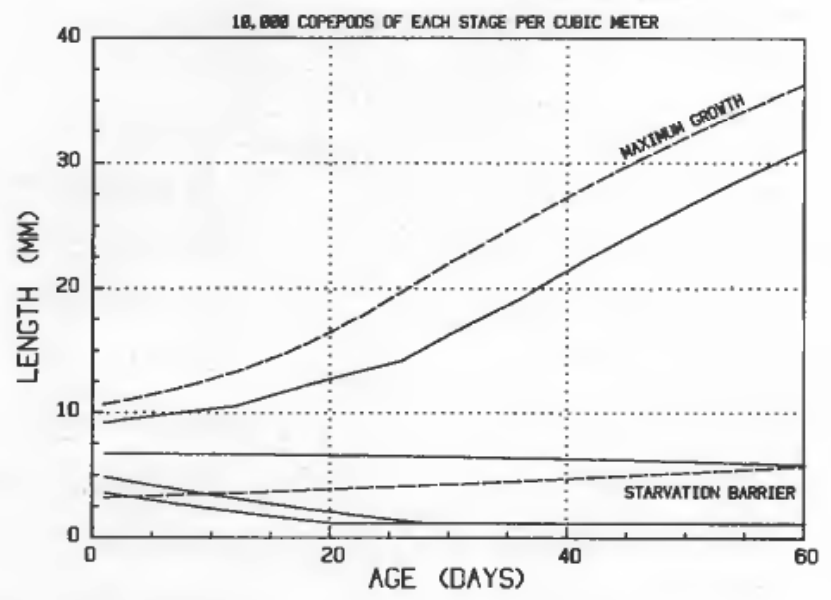

(a)

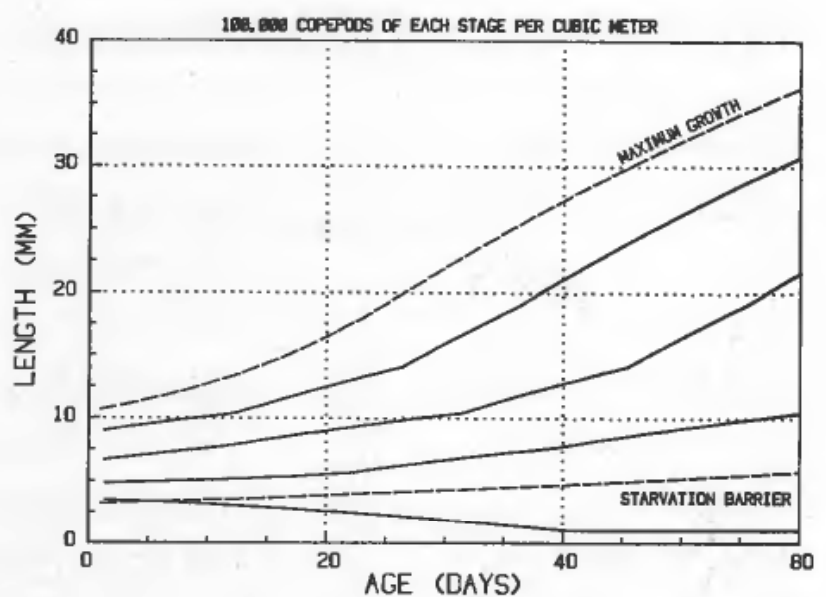

(b)

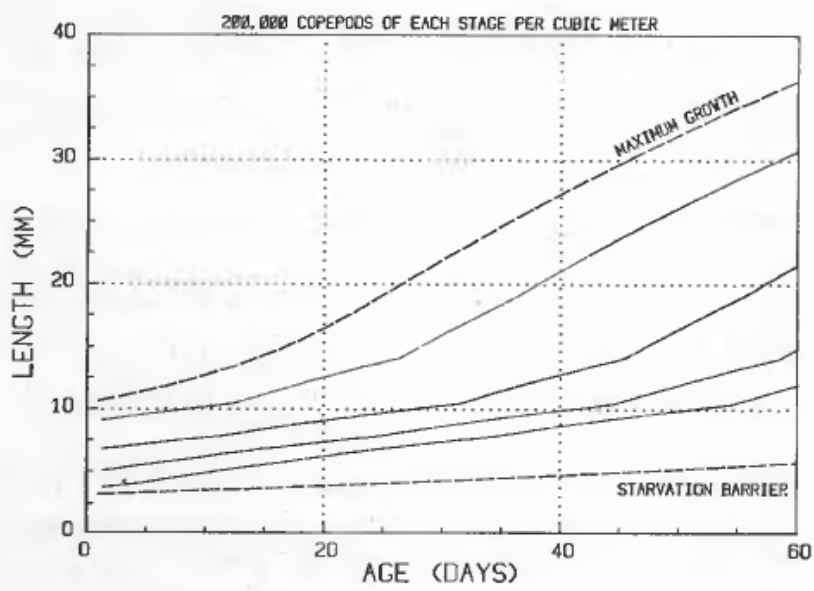

(c)

Figure $8(a-c)$. Simulated growth patterns for larval capelin of 4 different lengths at hatching, in 3 (constantly replenished) considerations of zooplankton. At the lowest concentration, only the largest larvae are able to capture enough eggs and nauplii to survive. Typical concentrations in the Barents Sea are on the order of a few thousand $/ \mathrm{m}^{3}$. Discontinuities in the curves occur due to discretization of zooplankton sizes. 
according to

$$
\frac{\partial L}{\partial t}+u \frac{\partial L}{\partial x}+v \frac{\partial L}{\partial y}+v_{L a} \frac{\partial L}{\partial a}+v_{L l} \frac{\partial L}{\partial l}=S_{L}-M_{L}
$$

The source term $S_{L}$ represents larvae hatching from eggs, whereas the sink term $M_{L}$ represents both mortality and larvae surviving long enough (60 days) to enter the 'adult' domain. $v_{L a}$ and $v_{L l}$ are ageing and length growth respectively. Equation (4) is solved using techniques discussed in $\S 5$.

\subsection{Adults}

(a) Introduction

From 60 days after hatching until death, fish are simulated in the adult domain. In addition to age, length, and position in physical space, they are now also distributed sexually (male, female) and in sexual maturation stages (immature to fully ripe). The length-related volumetric food searching ability is augmented by an implicit schooling behaviour, resulting in swimming patterns which are coherent on scales of weeks and hundreds of kilometres. Length growth, condition factor, reversible and irreversible storages of proteins and lipids, and factors relating to behaviour (preferred temperatures, satiation level, and reproductive hormone level), modeled through simple parameterizations, will eventually be simulated by a physiological model now under formulation. Exogenous factors (food, temperature, hydrodynamics, and predators) are also input via simple temporary submodels.

Larvae entering the adult domain at their then-current physical locations and sizes represent the only source of adult fish in the model, immigration being probably a negligible consideration for this stock (Prokhorov 1965; A. Dommasnes, personal communication). The division by sex of new adults is taken to be $50 \%-50 \%$, malefemale (Prokhorov 1965).

Sexual maturation of capelin occurs at different lengths and ages from year to year, the variations being probably dependent on food and temperature regimes over the previous years (Prokhorov 1965; Olsen 1968). Because of the incomplete state of the model system as a whole, the dimension of gonad development stage has been temporarily reduced to two distinct states: immature, and maturing or mature. Transfer of fish from the immature to the maturing state obeys a simple age-length parameterization. Thus the governing equation for an adult group $A$ of specified maturity stage and sex (e.g. maturing females) is

$$
\frac{\partial A}{\partial t}+\frac{\partial A \hat{u}}{\partial x}+\frac{\partial A \hat{v}}{\partial y}+\frac{\partial A v_{A a}}{\partial a}+\frac{\partial A v_{A l}}{\partial l}=S_{A}-M_{A}
$$

in which $\hat{u}$ and $\hat{v}$ represent advective plus active swimming components. $v_{A a}$ and $v_{A l}$ are ageing and length growth rates respectively. The eventual inclusion of a gonadal development term in eqn. (5) $\left(\frac{\partial A v_{A g}}{\partial g}\right)$ will reduce the number of equations to be solved in the adult domain to two (male and female), but will increase active memory storage needs for the extra discretized dimension. The source and sink terms, $S_{A}$ and $M_{A}$, on the right hand side of eqn. (5) contain potential coupling elements, since fish developing from an immature to a mature state must pass from the domain of one equation to that of another. 


\section{(b) Feeding, growth, and sexual maturation}

Although their physical locations may be different, adults and larvae share the same sea, and therefore potentially encounter the same size and spatial distributions of zooplankton. Maximum prey diameter $d(\mathrm{~mm})$ is related to fish length $l(\mathrm{~mm})$ by $d=0.05 l$, the same mouth size limitation imposed for larvae. Minimum prey weight is taken as $0.001 \%$ of body weight. The resulting range of acceptable prey sizes versus fish length, $l(\mathrm{~mm})$, for weight $w(\mathrm{gm})$ given by

$$
w=3 \cdot 16 * 10^{-7} * l^{3 \cdot 5}
$$

(estimated from Monstad 1971), is shown in Fig. 7, and seems in reasonable agreement with recent investigations of the Barents Sea capelin diet (Lund 1981). Within their specified size ranges, the fish are assumed to prefer the largest prey available down to a threshold density of 1 organism $/ \mathrm{m}^{3}$, at which time, if still unsatiated, the fish switch to the next smaller prey present in concentrations exceeding the threshold.

The maximum ration, $R_{\max }$, is taken as $5 \%$ of body weight, corresponding to maximum observed stomach fullness indices on the order of 500 in the autumn (Ibid.).

Details of food distribution, location, and consumption cannot be resolved by a physical grid system of the scale used here, and therefore require parametric representation. In lieu of a proper schooling submodel, the fish are assigned a lengthrelated volumetric searching ability, as in the larval domain (Fig. 7), with the additional ability to sense gradients over distances on the order of $100 \mathrm{~km}$. It has been demonstrated that individual fish have difficulty discerning local gradients (Larrick, et al. 1978; Stott and Buckley 1979), and cannot be expected to do better on the much larger scales considered here. Yet it is a fact that the capelin is successful in locating its unevenly distributed planktonic food; i.e. the stock survives from one year to the next. The hypothesis that capelin are able to sense such gradients through a schooling behaviour is discussed further in $\S 3.4(d)$.

Length growth is presently coupled in a primitive linear fashion to food intake. From Monstad (1971) maximum length growth rates of 0.13 and $0.11 \mathrm{~mm} /$ day have been estimated for males and females respectively. Although the data indicates a slower length growth rate for females, perhaps due to a greater demand for protein and energy in the developing gonads, this apparent difference may also reflect a younger female maturation age coupled with high post-spawning mortality (Prokhorov 1965, 1968). With the eventual inclusion of a detailed physiological model, it will be possible to investigate a variety of hypotheses in this area. The length growth increment $\Delta l$ for a given group of fish is calculated simply as

$$
A l=\frac{R(l, x, y, t)}{R_{\max }(l)} \Delta t
$$

The growth rate is therefore a function of length, physical location, and zooplankton densities. Temperature and food composition dependencies have been neglected.

Sexual maturation has been parameterized as a length-age relationship, using a qualitative fit to data from several sources (Prokhorov 1965, 1968; Olsen 1968). The minimum spawning length $l_{S P}(\mathrm{~mm})$ for males is taken to be

$$
l_{S P}=176 \cdot 5-66 \cdot 5 \exp (0-0.0013 t)
$$

for age $t$ in days. Females mature in the model at a length $20 \mathrm{~mm}$ shorter, assuming the differential to have been absorbed in the formation of reproductive products. 
Maturation in time appears to be highly non-linear, accelerating rapidly just prior to actual spawning (Prokhorov 1968). This suggests that a difficult, energy-consuming migration may be reflected in eggs with a below-average allotment of yolk, and therefore lower larval survival rates, a hypothesis that can be investigated with the inclusion of the physiological model. For the time being, maturation is approximated by a transfer of fish longer than $l_{S P}$ from maturation stage 1 (immature) to stage 2 (maturing or mature), implemented from August to February. This highly deterministic approach might be reasonable in a relatively stable environment in which food were non-limiting, but will require proper verification for the Barents Sea.

\section{(c) Mortality}

Two types of mortality are included explicitly in the model: post-spawning and predation. (Active or passive transport of capelin outside the physical boundaries of the model may be considered an implicit mortality from the standpoint of population dynamics.) For stock management purposes, it is assumed that no fish survive the spawning act (A. Dommasnes personal communication). In actuality some certainly do (e.g. Prokhorov 1965; Fridðgeirsson 1976), although there appears to be no consensus on the survival rate, which is probably dependent on sex and age as well as physical condition. Descriptions of the spawning act (e.g. Friogeirsson 1976) suggest that the male takes the brunt of the physical stress through repeated spawnings (versus probably only one per year per female), damage to the head, abdomen, pectoral, pelvic and anal fins resulting from abrasion against the substrate during the act of copulation and egg deposition. Males also show no reversal from mating dress, whereas females carry no physiological changes preventing spawning survival. Observations in aquaria (Ibid.) resulted in male and female survival rates of $0 \%$ and $5 \%$ respectively. Samples of dead fish on spawning grounds often consist entirely of males (Ibid.; Bakke and Bjørke 1973), whereas schools some distance from spawning grounds have been observed to consist of almost $100 \%$ spent females (Prokhorov 1960; Vilhjálmsson 1974). The spawning mortality in the model is currently set at $100 \%$ for both sexes, but the apparent gap in our knowledge certainly invites future hypothesis testing in this area.

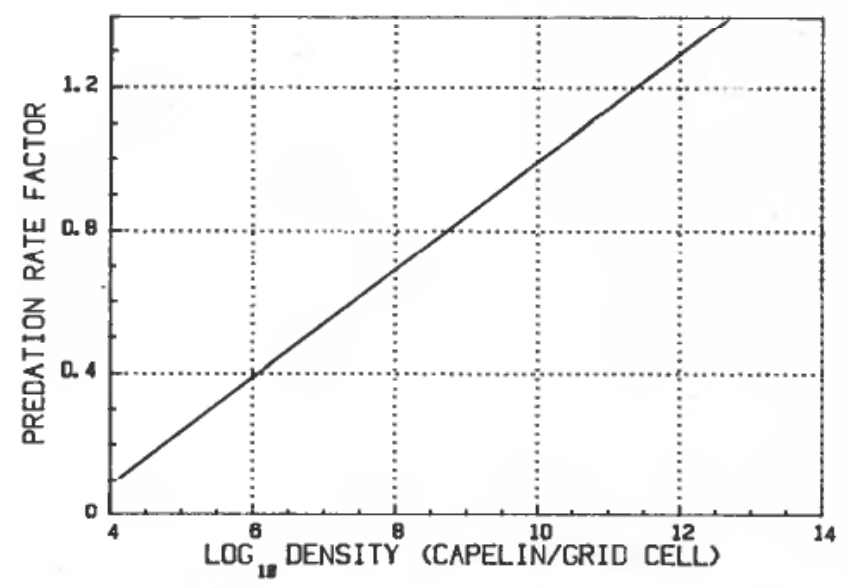

Figure 9. Suggested density dependent predation factor parameterization for cod and marine mammals. Further field research is needed to properly model these interactions. 
Cod, minke whales, harp seals, and man, the major capelin predators in the Barents Sea (Dommasnes, Jakobsen, Bergfløt, Christensen personal communication; Jangaard 1974; Ponomorenko et al. 1978) are included as predators in the model. Each of these submodels is discussed in detail in $\S 4$. Cod and marine mammal predation is limited by the density dependent formulation shown in Fig. 9.

\section{(d) Behaviour}

At the level of the individual, there is in general a set of competing external states $v$ (e.g. food, light, temperature) to which a compromise spatial response $\dot{\boldsymbol{r}}$ is made. The physiochemical state $\boldsymbol{x}$ of a healthy fish acts as a complex integration system which produces that response which has been historically optimal for the population (Kerr 1971; Milsum and Roberge 1973; Balchen 1979). From the modeling standpoint, the problem is to reduce this complicated interaction between the individual organism and its environment to a manageable level of abstraction which $(a)$ is identifiable, in the sense that necessary parameters are obtainable through observation and experimentation, and $(b)$ permits the juxtaposition of behaviour stimuli dynamically in space and time, so that a correct set of hypotheses concerning behavioural functions and causes produces a correct simulation of behaviour.

Specific hypothesized relationships among the components of $\boldsymbol{v}$ and $\boldsymbol{x}$ imply a set of 'comfort surfaces' $C_{i}$ in $v-x$ space (Balchen 1979). An agglomeration of fish at a certain time can then be located in a spatially variable comfort map $C$ which is the net effect at each point of all the $C_{i}$, and within which a migration velocity $\dot{r}$ is oriented along the steepest positive gradient. Here a simple superposition of the $C_{t}$ is proposed, in which the contribution from each is scaled according to its relative importance at the time.

As a starting point, we take the vector of environmental stimuli $v$ to include food density, temperature, light, direction and magnitude of ocean current, and capelin density. Others, such as predator pressure, are certainly active at least on small, localized spatial scales, and can be incorporated if desired.

$C_{1}$ and $C_{2}$, the dependence of comfort on temperature and food concentration, follow the forms suggested by Balchen (1979). The equation relating comfort to temperature $T\left({ }^{\circ} \mathrm{C}\right)$ is

$$
C_{1}=1-\left(\frac{\alpha_{1}}{P_{1}+1}\right)\left(\frac{T-T_{\mathrm{opt}}}{T_{\max }-T_{\min }}\right)^{2}
$$

in which $P_{1}$ is a measure of the sensitivity to deviations from the physiologically preferred, or optimal temperature $T_{\text {opt }}$, as reflected perhaps in glycolysis or lipogenesis rates (Hocharka and Somers 1971). $T_{\max }$ and $T_{\min }$ reflect the range of temperatures in which the fish are normally found, and $\alpha_{1}$ is a surface shape parameter. As $\boldsymbol{P}_{1}$ increases, the sensitivity of the fish to deviations from the optimal temperature, which may itself be a function of $\boldsymbol{P}_{1}$, decreases. For the Barents Sea capelin we estimate $T_{\max }$ and $T_{\min }$ at $5^{\circ} \mathrm{C}$ and $-1.5^{\circ} \mathrm{C}$ respectively (Hamre and Monstad 1980; Loeng 1981; Dommasnes and Olsen 1974; Monstad and Kovalyov 1973). In lieu of explicit physiological inputs, the optimal temperatures for maturing and immature fish are assigned according to the curves of Fig. 10. Maturing fish may need low summer and autumn temperatures to control maturation rates, and higher spring temperatures for metabolic rates high enough to support spawning activity, whereas the immature fish may have a similar preference pattern of reduced variability. 


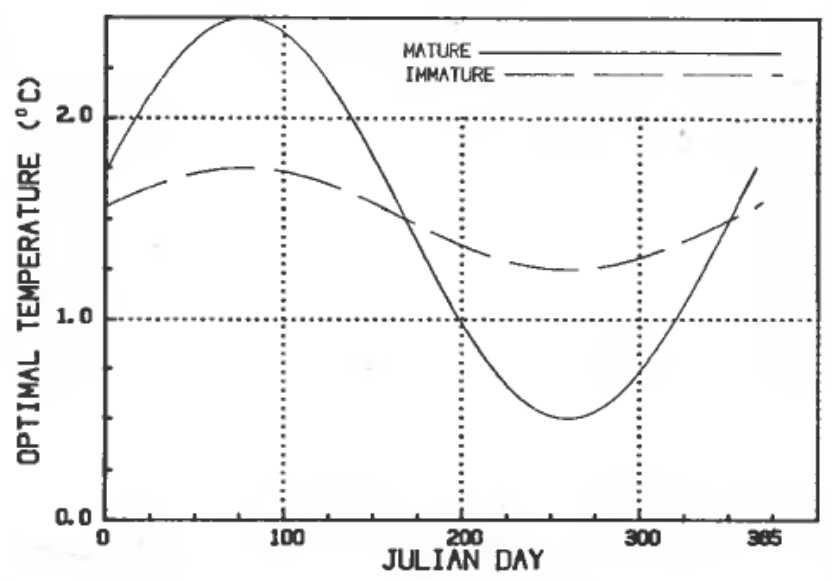

Figure 10. Hypothesized preferred (optimal) temperatures for mature and immature capelin. That larger fish appear to prefer colder water than smaller fish in autumn is supported by Loeng (1981). The reverse pattern in spring may be required to support the high metabolic activity for spawning.

The equation for $C_{2}$, the contribution of food density $d_{z}$ to comfort is

$$
C_{2}=d_{z}{ }^{1 / 2} /\left(1+\alpha_{2} P_{2}{ }^{2}\right)
$$

in which $P_{2}$ is a measure of the satiation level, as reflected in energy stored in the stomach and serum, and $\alpha_{2}$ is a coefficient. This parameterization simply reflects the fact that as the fish nears satiation, the importance of food density to its immediate sense of comfort decreases.

The effect of light on vertical migration has been neglected here, since the time scales of these movements (circa 6-12 hours) are not resolved in the population model, which normally operates on a timestep of 1 to 3 days. In the horizontal, a sunoriented migration stimulus is hypothesized for the adult-capelin, such as that supported experimentally for salmon (Stepanov, Churmasov and Cherkashin 1979), and suggested theoretically for herring (Balchen 1976). Lacking an adequate hormonal model, a simple parameterization is used in which the comfort $C_{3}$ associated with swimming towards the light source, is

$$
C_{3}=\alpha_{3} G \exp \left[-t_{2} / t_{0}\right]
$$

in which $G$ is gonadal development stage defined on the interval $[0,1], t_{2}$ is the number of Julian days before or after March 1 , and $t_{0}$ reflects the temporal duration of the effect.

The capelin are modeled as swimming against the currents simulated by the hydrodynamic model at a proportional speed. The effect is therefore stronger in faster flowing areas. Although it appears obvious that a single fish in midwater in a large ocean will be unable to sense the direction of the major currents, there are at least two possible mechanisms by which the Barents Sea capelin can do so. First, the adults appear to perform fairly regular diurnal migrations in the vertical throughout the year, being found between 50 and $100 \mathrm{~m}$ during the night, and down to 200 or more m during the day (e.g. Dommasnes, Midttun and Monstad 1979; Lund 1981). Even small schools of $10 \mathrm{~s}$ of metres in dimension will experience distortion due to shears in horizontal planes during such vertical movements. The displacement of fish 
relative their neighbours in the school could produce an accelerating response for the school as a whole. Secondly, as discussed below, it is observed that the capelin often form scattering layers extending for hundreds of kilometres (J. Hamre personal communication). The function of this behaviour is not well understood, but may be a means by which the capelin is able to sense such dynamic events as ocean currents. The flow of stimuli will certainly be slower than in smaller, denser schools, but the mechanism, that of a fish immitating the behaviour of its neighbours, remains the same. Further research is needed in this area to test this hypothesis, and to measure the response lag times, which have been neglected here.

The fifth behaviour form included in the model is this tendency to agglomerate or school, a form of behaviour perhaps evolved in the capelin for the purpose of achieving improved sensitivity to environmental gradients which are non-uniform in space and time, as well as for possible hydrodynamic, protective or navigational gains. Included here under the definition of schooling behaviour are capelin aggregations as observed on scales of a few hundred metres to several hundred kilometres in horizontal dimensions, and in densities from perhaps $1 \mathrm{fish} / \mathrm{m}^{3}$ in the largest distributions, up to 50 or more during spawning (Miller and McInerney 1978; Sætre and Gjøsæter 1975; Bakke and Bjørke 1973). Although various types of capelin agglomerations have been characterized descriptively (Atkinson and Carscaddin 1979; Lund 1981), the fact remains that little is known about their functional purposes. Lacking input from a tested schooling submodel, it must temporarily suffice to estimate minimum and maximum capelin densities, and assume some simple preference relations.

The distribution of capelin will in general be discontinuous over the $40 \mathrm{~km}$ physical grid scale used here. The problem of parameterizing minimum density suggests estimating probabilities concerning minimum optimal size and number of schools to be found within a certain area given the environmental conditions, being defined perhaps as that size and number which feeds the most fish in the least time by $(a)$ limiting competition, and $(b)$ permitting rapid information transfer rates to locate and respond to gradients in the field. School size must also relate to prey distribution, since searching success increases with school size, until the school becomes so large that some members do not get enough to eat before a typical zooplankton patch is consumed.

Noting that capelin school at the lowest light intensity for dark adapted human vision, but fail to do so in total darkness (Miller and McInerney 1978), one criterion for minimum fish density is given by the maximum visual perceptive distance over which members of a school can maintain visual contact. This constraint can be relaxed somewhat by allowing the contact to be intermittent, the interval between successive sightings being a function of purpose. In the formation of a scattering layer, or veil, in which the agglomeration as a whole may move very slowly (the function being to locate the food gradient, for example), the frequency of contact could be on the order of once every second or two, whereas a school performing highly directional activity such as migration must be more closely packed, achieving essentially constant contact. In this latter case, the agglomerations can also be expected to be somewhat smaller, so that 'information' is passed quickly from one extreme of the school to the opposite. If the formation of such scattering layers is an information transfer mechanism at some level between the individual school and the entire population, it can be inferred that enough fish must be within a given area to transcend the area without losing contact. Such formations are typically $10 \mathrm{~m}$ thick and contain on the order of $0.5 \mathrm{fish} / \mathrm{m}^{3}$ (J. Hamre personal communication), so that 


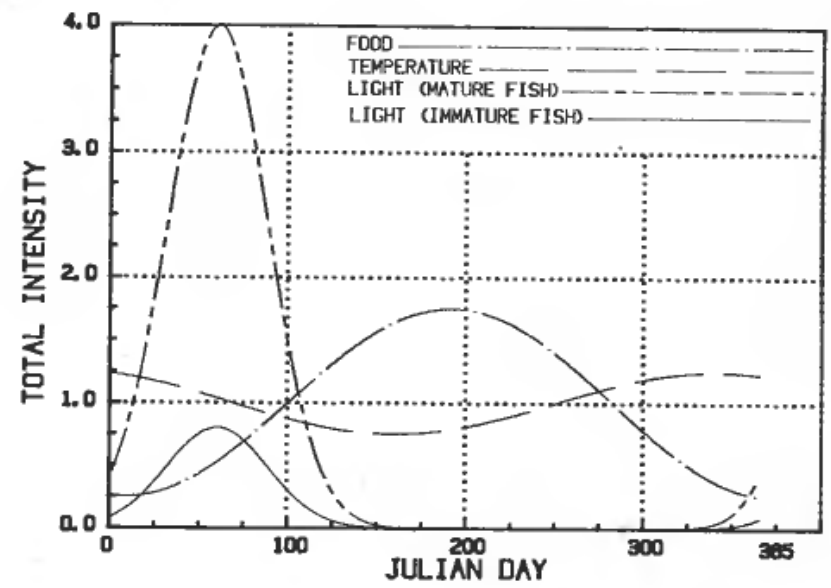

Figure $11(a)$. Parameterized intensity levels associated with light, food and temperature. The effect of the sexual (light) hormone is much lower for the immature fish.

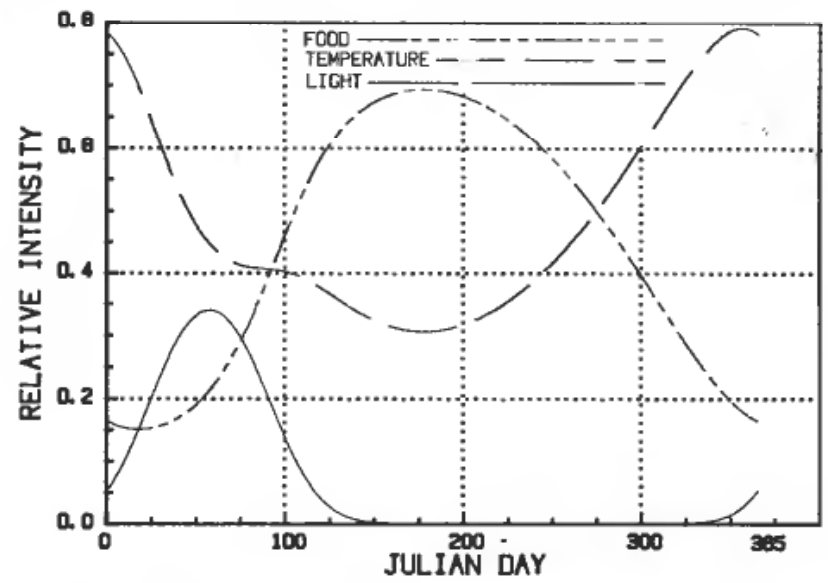

Figure $11(b)$. Implications of the hypothesized relationships of Fig. $11(a)$ for immature fish. The curves are scaled so that the sum of the ordinates is always unity, making the relative importance of each effect more clear.

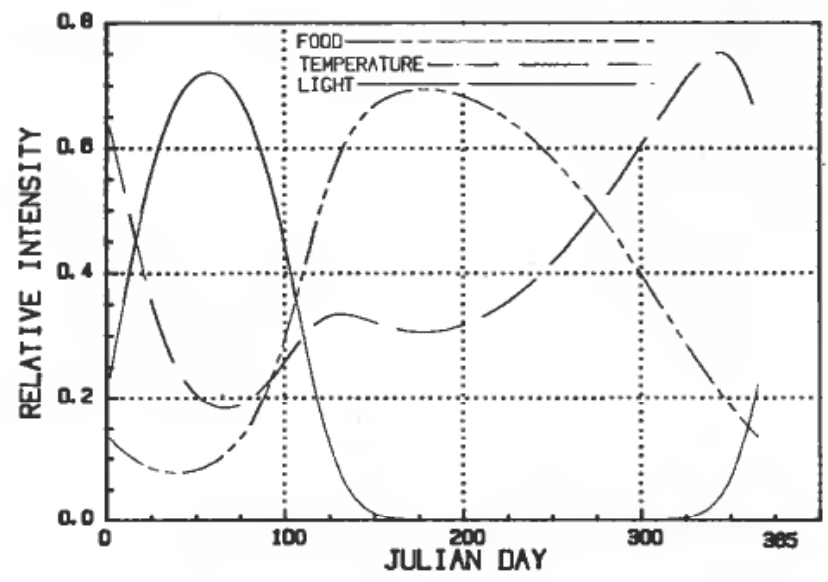

Figure $11(c)$. As in Fig. $11(b)$ but for mature fish. 
a $40 \mathrm{~km}$ grid size requires a minimum of about $10^{10}$ fish per cell. This assumes continuous distributions, and appears very restrictive. The numerical limitation (§5) of $10^{7}$ is used instead, allowing for schooling on subgrid scales. If a migration due to any stimulus would leave fewer than this number, then the remaining fish are also assumed to follow the migration (i.e. the grid cell is emptied). The upper limit to density could reasonably be expected to relate to resource availability (e.g. food, oxygen), and the inclusion of feeding behaviour in the model suffices to control fish densities above the minimum level.

The five comfort fields calculated for a given system state (fixed values of $v$ and $x)$ are normalized on the scale $[0,1]$, corresponding to minimum and maximum comfort, scaled, and superimposed to produce the field of total comfort which determines swimming velocities $\dot{\boldsymbol{r}}$. This relative scaling is performed according to the ordinates of the curves shown in Fig. 11. The low amplitude oscillation in the sexual hormone level for immature fish induces a 'trial spawning run' as has been reported for the immature of other teleosts (Harden Jones 1968). Because swimming speeds are length dependent, any movement of sufficient duration will effect a length separation, so that larger fish will be found farther north during a feeding migration, and arrive first at the spawning grounds in the spring. The oscillations in food importance are intended to reflect the effect of large fat storages and low metabolic rates during the winter.

\section{Exogenous model details (*)}

Following are descriptions of the temporary submodels used to provide a simulated dynamic environment in which to test the capelin population model.

\subsection{Physics (*)}

The physical environment has been approximated as a vertically averaged system, governed by a single net transport velocity field (Fig. 12) produced by the threedimensional hydrodynamic model being developed for the system (Bernsten et al.

MAXIMUM VELOCITY $10.3 \mathrm{KM} / D A Y$

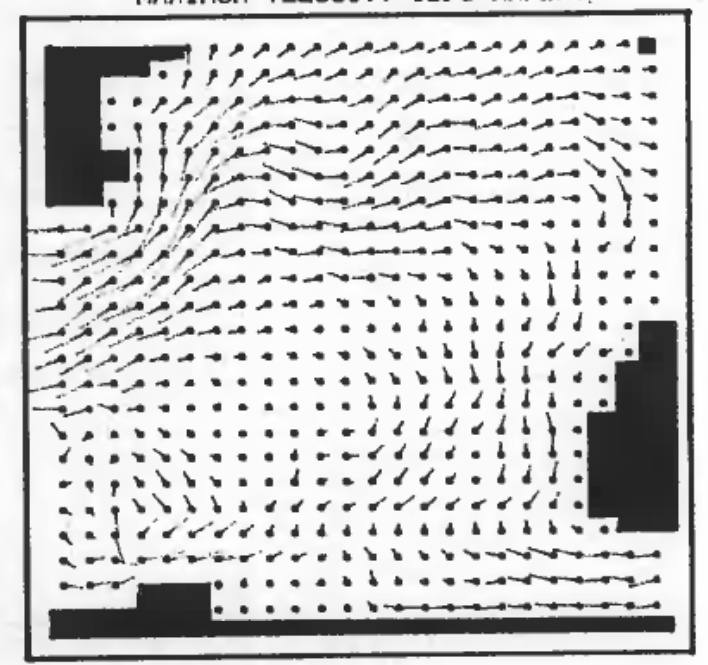

Figure 12. Two dimensional velocity field used for simulation exercises. 
1981). This field corresponds to the top $25 \mathrm{~m}$ layer at one timestep of a trial run of that model, modified so that the horizontal divergence is zero throughout the field, and probably over-estimates transport rates at the deeper (50 to $250 \mathrm{~m})$ depths in which the adults are usually found. The effects of diurnal vertical migrations, characteristic of the plankton as well as the adult capelin, on net transport cannot be investigated with this simple system. The current pattern used shows qualitative agreement with estimates of the long term transports in the Barents Sea (Anon. 1958; Novitskiy (1961).

The seasonal advance and retreat of the sea ice, important in limiting primary production through its interception of light, as well as its effects on air-sea interactions, is simulated as an arc centred at grid cell $(1,1)$ with a radius $(\mathrm{km})$ given by $800+$ $350 \sin \left(\pi\left(t_{1}-180\right) / 182 \cdot 5\right)$. Ice coverage is therefore least at the end of the summer (September), and greatest in March, in agreement with average condition for the decade 1966-1975, as reported by Loeing (1979). Four seasonal locations of this simulated ice edge are shown in Fig. 13.

The dynamics of water temperature are approximated based on information from Harvey (1964), and seasonal biological surveys which include descriptive hydrographics, performed by the Norwegian Fisheries Directorate (e.g. Hamre and Monstad 1980). The transport equation

$$
\frac{\partial T}{\partial t}+u \frac{\partial T}{\partial x}+v \frac{\partial T}{\partial y}+\frac{\partial H}{\partial t}=0
$$

in which temperature $T\left({ }^{\circ} \mathrm{C}\right)$ is defined at the grid centres, and $H$ represents heat lost to the atmosphere, is solved in the finite difference manner described in $\S 5.1$. The temperature at the lower left grid cell (Fig. 3) is given as a function of Julian Day $\left(t_{1}\right)$ as $6.0-1.5 \sin \left(\pi\left(t_{1}-90\right) / 182.5\right)$, and at the lower right grid cell (south of Novaya Zemlya) as $1.0 \sin \left(\pi\left(t_{1}-90 / 182 \cdot 5\right)\right.$. The temperatures at the two northernmost corners are held at $-1 \cdot 0$, and a linear interpolation is performed along each edge. The values at the boundaries are determined at the beginning of each timestep, prior to advection, by using a weighted average between the linearly interpolated driving value, and that calculated at the boundary grid at the end of the previous step. This assures smooth transitions of temperature near the physical boundaries. The weighting ratio between interpolated and calculated values is 3 to 1 . The heat loss rate is parameterized as being related to the difference between water and air temperatures by a constant proportionality $(0.002$ per day). Atmospheric temperature at the southern boundary $\left({ }^{\circ} \mathrm{C}\right)$ is approximated by $15.0 \sin \left(\pi\left(t_{1}-120\right) / 182.5\right)-5 \cdot 0$, is taken at $5^{\circ} \mathrm{C}$ colder along the north, and linearly interpolated inside the field. Started up from a uniform temperature field of $0^{\circ} \mathrm{C}$, this simple system reaches a limit cycle after about four years' simulation (Figs. $16(a-d)$ ), and is used in this form.

\section{2. $\operatorname{Cod}(*)$}

A cod population model will later be constructed on the same conceptual format as that described here for the capelin model. Presently, the two-level system outlined in Fig. 14 is used, in which the population is agglomerated as immature and mature biomass components, with recruitment following a density dependent Ricker function. The immature portion is always in the Barents Sea, whereas the mature stock migrates south along the Norwegian coast to spawn in the Lofoten Island area during February, March and April, after which they return to the Barents Sea to feed. 

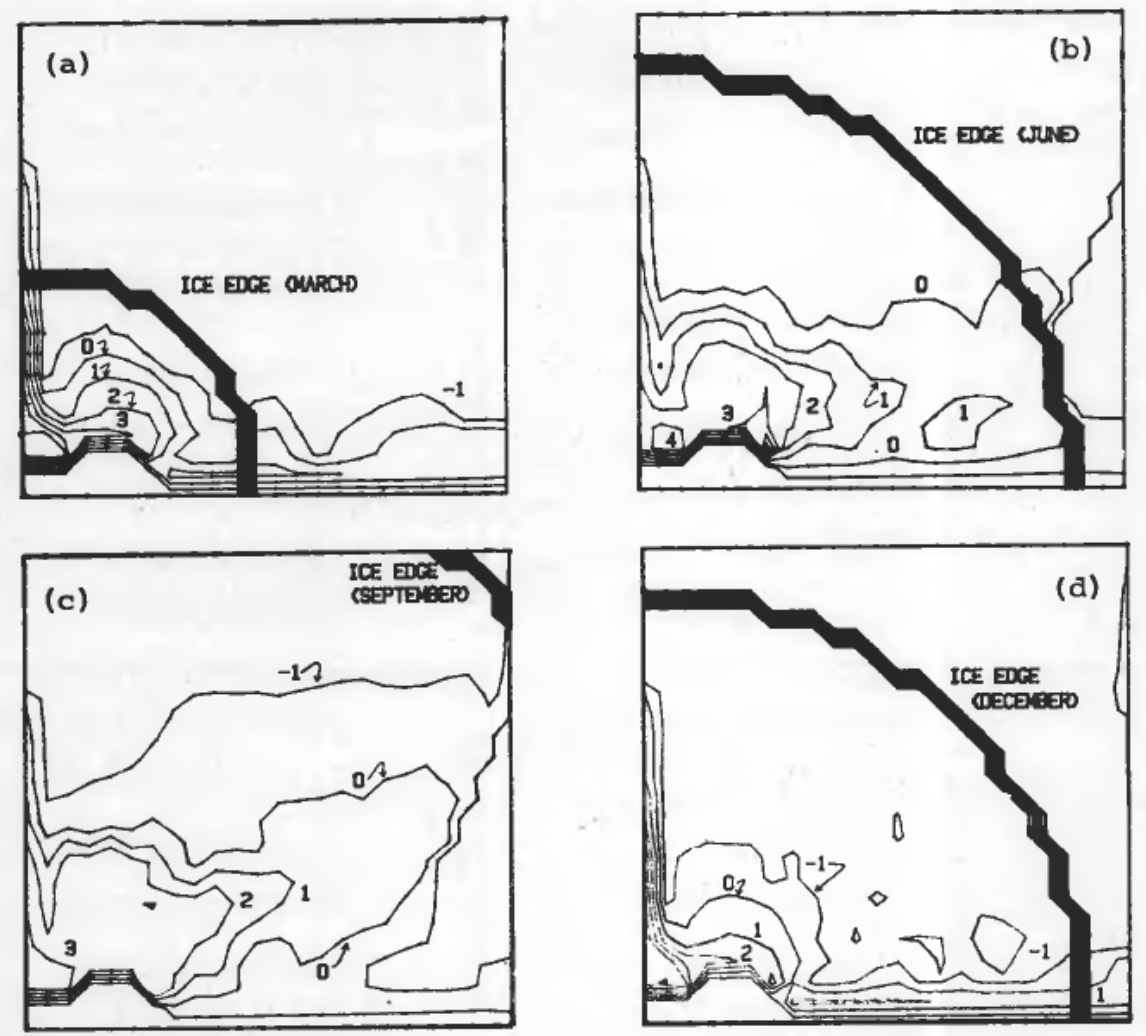

Figure $13(a-d)$. Temperature fields as similated in March, June, September, and December. The ice edge is shown as a heavy line, with ice to the north and east, open water to the south and west.

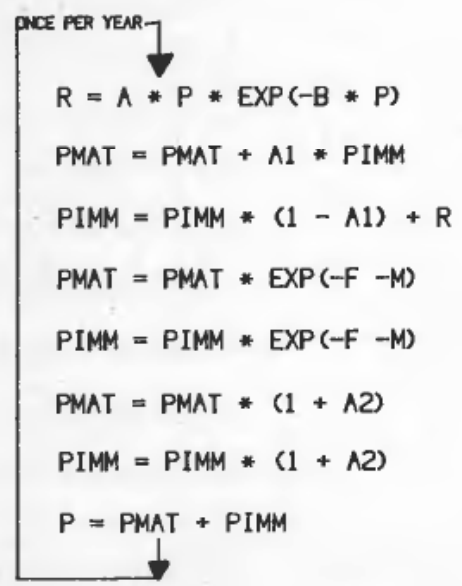

NEW RECRUITS

MATURATION

RECRUITMENT

MORTALITIES

MORTALITIES

GROWTH

GROWTH

TOTAL STOCK BIOMASS

Figure 14. Schematic of the Arcto-Norwegian Cod Stock Biomass Simulator. $(R=$ recruits; $P M A T=$ mature adult stock biomass; $P I M M=$ immature biomass; $A, B$ parameters in Ricker Recruitment function; $A 1, A 2, F, M$ maturation, growth, fishing mortality, and natural mortality rates respectively.) For $A=0.82, B=3.0 \times 10^{-7}$ per ton, $F=0.35$ per year, $M=0.2$ per year, $A 1=0.2$ per year, and $A 2=0.35$ per year, the total equilibrium stock is $3 \times 10^{6}$ tons. 
During August and September, both mature and immature components of the stock are distributed as far north as $74^{\circ} \mathrm{N}$ latitude (Ponomorenko, et al. 1978; Harden Jones 1968), although they appear much more heavily concentrated nearer the Finnmark coast during the winter and early spring, while the capelin are spawning (e.g. Anon. 1979; Anon. 1975). The present size of the stock is estimated at 3.0 million tons, of which approximately $20 \%$ is 7 years old or older and can be considered mature (Anon. 1979, 1981; Jakobsen 1978 a, b).

Soviet researchers report that predation by cod (and to a lesser extent haddock) on capelin occurs primarily during the spawning season (February-May) in the southwestern Barents Sea (Ponomorenko, et al. 1978; Ponomorenko and Yaragina 1978). The highest predation rates for the northwestern and northcentral regions, the capelin summer feeding grounds, are in July, August and September. The frequency of occurrence of capelin in cod stomach was found to vary on an average, annual basis from $10 \%$ to $50 \%$, with peaks about once every decade. The mean value for cod for the year 1947-1976 was about $30 \%$, versus about $10 \%$ for haddock. An increasing trend in the annual average values is attributed to a decline in the herring stocks, hence an increased reliance on the capelin. Estimated consumption of capelin by cod for the years 1974-1976 was estimated at 6.3, 7.4 and 9.5 million tons respectively, implying a daily predation rate on the order of $0.007 \mathrm{~kg}$ per $\mathrm{kg}$ cod. Predation by haddock, estimated at about $2 \%$ of this rate, is neglected here.

The presence of the mature portion of the stock in the Barents Sea is modeled in proportion to $\sin \left(\pi\left(t_{1}-160\right) / 182 \cdot 5\right)$, giving a maximum in August. The sum of this fraction of the mature stock plus the immature component is then uniformly distributed from east to west in the physical model, and as an exponentially decaying function from south to north.

The predation of cod on capelin is parameterized on the assumption that the typical average consumption rate will be exceeded if capelin are extremely dense (e.g. during spawning), and not met if they are sparse. The average predation rate is therefore multiplied by

$$
0 \cdot 09 \log _{10} N+0 \cdot 1
$$

in which $N$ is the number of capelin in the physical grid cell. The density dependent function is graphed in Fig. 9.

\subsection{Marine mammals (*)}

Of the many types of marine mammals found in the Barents Sea, the two most important in terms of their interaction with the capelin stock are thought to be the minke whale and the harp seal (Christensen, Bergfløt and Øritsland personal communications). Because of the relative longevity of both (circa 25 years each), the populations can be considered relatively stable (Benjaminsen 1979; Rørvik 1981).

For a seal population size of 1.2 million, a typical adult weight of $100 \mathrm{~kg}$, a food intake rate of $5 \%$ body weight per day, of which perhaps $50 \%$ is capelin, the seals account for approximately 3 million $\mathrm{kg}$ per day. These seals are found in the open ocean, as well as near land, and have annual feeding migrations into and out of the Barents Sea. Because of uncertainty concerning physical distributions of seals we apply a simple uniform distribution over the open (un-iced) portions of the model ocean.

The minke whale, which is in the Barents Sea from May to October, has a population size of approximately 100,000 (Rørvik 1981, Christensen and Rørvik 1980, 
1981). If average body weight is $7000 \mathrm{~kg}$, and consumption rates are similar to those for seals, then the whales reduce the capelin biomass by up to 18 million tons per day. As with the seals, the physical distribution of whale biomass present at any time in the sea is taken to be uniform over open water. The total biomass present follows a clipped sinusoidal function with a maximum of $100 \%$ in July, and equal to $0 \%$ from November 1 to April 30 (Anon., 1958). The predation rate of the mammals is subject to the same density dependent modifications as that used for the capelin-cod interaction (Fig. 9).

\subsection{Fishing (*)}

To investigate alternatives for stock management, it is necessary to model fishing fleet activity explicitly. The Barents Sea capelin fishery can be characterized as a purse seine fishery, trawlers taking less than $20 \%$ of the annual catch (S. Sætre personal communication). The fleet uses a scouting group, composed of research and commercial vessels, to locate the spring spawning migration. Each boat also carries a searchlight sonar capable of locating capelin schools up to $1 \mathrm{~km}$ on either side of the course. The fleet, composed of some 200 boats with cruising speeds of 10-12 knots and capacities ranging from 50 to 1500 tons, therefore represents quite an efficient fishing system.

The total annual quota is set subject to the results of a Soviet-Norwegian stock survey. The Norwegian quota is then divided among the boats licensed to participate in the capelin fishery, a number which is somewhat variable from year to year. There are several processing factories in Norway, some of which are over $1000 \mathrm{~km}$ from the fishing grounds. During the summer, when the capelin are at the northern limit of their range, transport distances can be especially long. Although the actual finding and catching of enough capelin to fill the hold (typically 650 tons) may require only a day or two, transport, unloading, re-equipping and bad weather can cost an additional week or more per trip. It is assumed that a commercial vessel will not make a set unless it can take at least $10 \%$ of its capacity; that fishermen strictly observe the $11 \mathrm{~cm}$ size limit; that males and females are fished equally; that fishermen know, from experience, scouting information, and observation of other boats, where the fish are, so that searching on scales larger than physical grid lengths $(20$ to $40 \mathrm{~km})$ is negligible or safely accounted for in travel time; that the boats fish the highest concentrations first, and that total capacity available for fishing at any time (i.e. not travelling, unloading, refitting, etc.) is distributed over the fishing grounds in proportion to the density of capelin exceeding the length limitation, subject to a preference for the southernmost concentrations, requiring the least travel time. Characteristics of the 'standard boat' used to characterize the fleet are given in Table 1.

The threshold assumption for fishing activity implies both a minimum concentration of fish (estimated at 20 per $\mathrm{m}^{3}$ ) and a minimum school size. If a school is $20 \mathrm{~m}$ thick, approximately round, and a set of the net can be expected to take $50 \%$ of the school, then the minimum horizontal dimension is about $60 \mathrm{~m}$.

Sizes, depths, and fish densities in schools vary seasonally from place to place as well as daily within a given agglomeration. As discussed in $\S 3.4(d)$, echograms commonly show the capelin either as extensive scattering layers at depths of 50 to $100 \mathrm{~m}$, continuously distributed in the horizontal, and up to $50 \mathrm{~m}$ thick, with densities on the order of 0.5 to $1 \mathrm{fish} / \mathrm{m}^{3}$, or as discrete schools. These schools are most typical of the mature capelin during the spawning migration, and may have densities exceeding $50 / \mathrm{m}^{3}$. Smaller, less dense schools are also found throughout the year, there being 


\begin{tabular}{|c|c|c|}
\hline Parameter & Description & $\begin{array}{l}\text { Estimated } \\
\text { average } \\
\text { value }\end{array}$ \\
\hline$T_{S}$ & searching time plus actual fishing time & 2 days \\
\hline$T_{T}$ & $\begin{array}{l}\text { travel time to and from fishing grounds } \\
\text { (includes refitting, unloading, and time } \\
\text { spent waiting out bad weather) }\end{array}$ & 6 days \\
\hline$V C$ & vessel capacity & $6 \cdot 5 * 10^{5} \mathrm{~kg}$ \\
\hline$V S$ & vessel cruising speed & $\begin{array}{l}500 \mathrm{~km} / \mathrm{day} \\
(11-12 \mathrm{knts})\end{array}$ \\
\hline FMIN & $\begin{array}{l}\text { minimum acceptable catch per set of the } \\
\text { purse seine (or trawl) }\end{array}$ & $0 \cdot 1 * V C$ \\
\hline$N B$ & number of boats (fleet size) & 200 \\
\hline
\end{tabular}

Table 1. Basic parameters in the fishing submodel characterizing the 'standard boat' and fishing fleet.

a relatively continuous transformation process back and forth between the scattering layer and distinct school states. Since it is the denser schools which are of interest to the fishermen, it is necessary to make some assumptions to parameterize fish behaviour (school formation) on the subgrid scale. For the nonce, the simple approximation is made that for immature fish, and maturing fish as well during the summer and autumn, approximately $30 \%$ of the time is spent in distinct schools, that where such schools occur, the frequency is once per $100 \mathrm{~km}^{2}$, and that typical sizes are $50 \mathrm{~m}$ thick by $500 \mathrm{~m}$ in horizontal dimension. This implies that, at a density of $20 \mathrm{fish} / \mathrm{I}^{3}$, perhaps $10^{9}$ fish in a $40 \times 40 \mathrm{~km}$ grid cell exist in fishable formations in the model. During the winter and spring, the entire spawning stock is assumed vulnerable $100 \%$ of the time.

\subsection{Zooplankton (*)}

The zooplankton section is a much simplified version of a published model (Slagstad 1980) which will eventually be incorporated into the total ecosystem simulation. The basic structure is based on the dynamics of the copepod Calanus finmarchicus, the most common calanoid copepod in the Barents Sea. Calanus eggs and nauplii constitute about $95 \%$ of the diet of young capelin larvae (Bjørke 1976). Older stages make up between $15 \%$ and $30 \%$ of the caloric intake of adults (Prokhorov 1965; Lund 1981). Since krill (Euphausiacea) constitute the bulk of the difference, a simple subsection has been added here to simulate that population.

The transport equation for zooplankton concentration $z$ is

$$
\frac{\partial t}{\partial t}+u \frac{\partial z}{\partial y}+v \frac{\partial z}{\partial y}+v_{D} \frac{\partial z}{\partial D}=S_{z}-M_{z}
$$

$v_{D}$ is the development rate in the developmental-stage dimension $D, S_{z}$ represents recruitment to the population (eggs), and $M_{z}$ represents losses due to mortalities. 


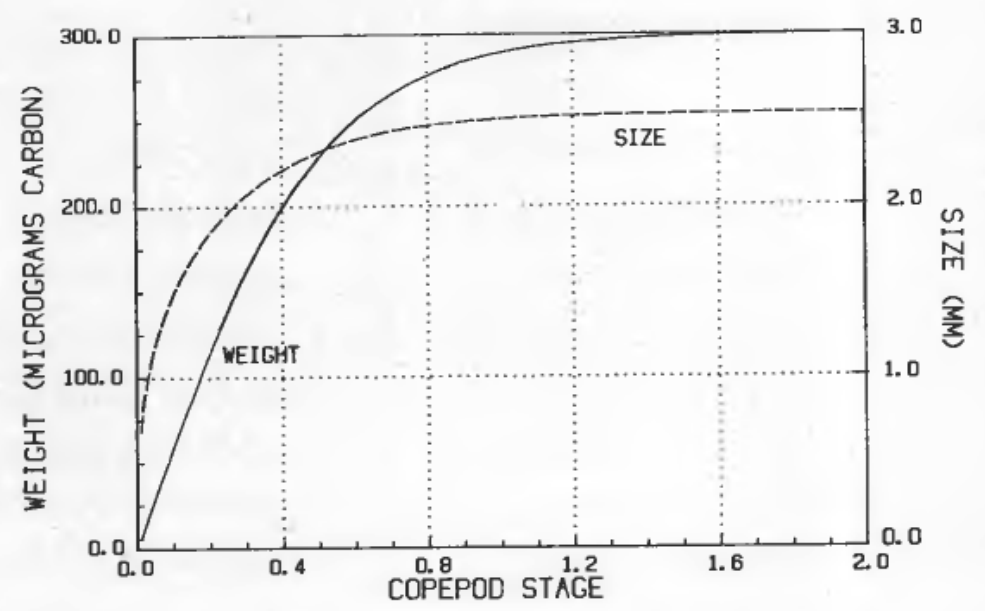

Figure 15. Size, weight parameterizations for copepods.

The weight-developmental stage relationship used for copepods (Fig. 15), estimated from Slagstad (1980), is

$$
w_{z}=300 \tanh (2 D)
$$

in which $w_{z}$ is $\mu \mathrm{g}$ carbon, and $D$ is developmental stage. Figure 16 shows the proportion of total development time $A(D)$ spent in each copepod stage.

Developmental time is approximated by

$$
t_{D}=140 \exp (-0 \cdot 13 T)
$$

in which $t_{D}$ is in days, and $T$ is temperature in ${ }^{\circ} \mathrm{C}$. Using information compiled from Zenkevitch (1963) and Wiborg (1954), the first day of egg production for copepods is estimated to be March 15 along the Finnmark coast, and July 15 in the northern Barents Sea. The length of the egg production season in the south is taken as 90 days, declining to 10 days in the far north. Intermediate values are obtained by linear interpolation from south to north. The egg production rate is set at 10 per day per adult female (Marshall and Orr 1972). Eggs are entered at the lower end of the weight curve.

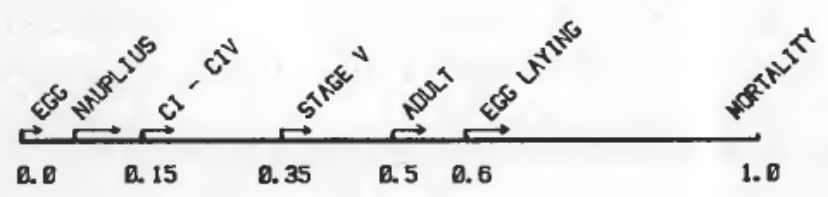

FRACTIONAL DEVELOPMENT SCALE

FOR COPEPODS

QFTER SLAGSTND, 1990

Figure 16. Fraction of a copepod's life spent in each successive stage (after Slagstad 1980). 

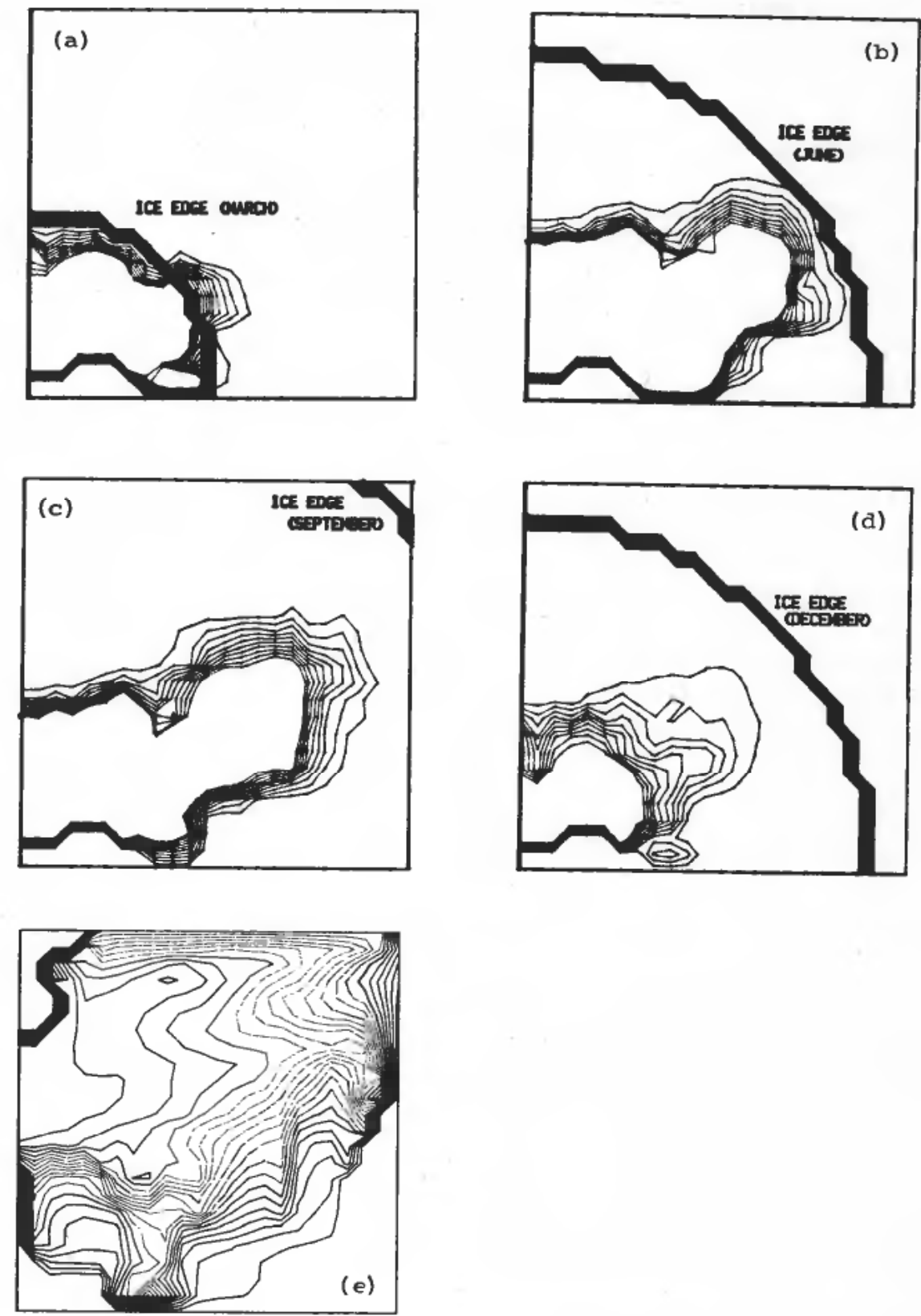

Figure $17(a-d)$. Copepod biomass distributions (in the absence of fish predation) for March, June, September, and December respectively. The ice edge is shown as a heavy line. The presumed maximum carrying capacity due to nutrient limitations is $25 \mathrm{~g} / \mathrm{m}^{2}$ averaged over a grid cell. The current flowing up the coast of Norway and into the Barents Sea at the lower left serves as a source of both warm water and nutrients (contour intervals: $2.5 \mathrm{gm}$ wet $\mathrm{wt} / \mathrm{m}^{2}$ ).

Figure $17(e)$. Distribution of krill (in the absence of predation) reaches this approximate equilibrium distribution of biomass, in which transport and regeneration balance each other. Boundary inputs are held at zero (contour interval $100 \mathrm{gr}$ wet $\mathrm{wt} / \mathrm{m}^{2}$, maximum $2500 \mathrm{gr}$ wet $\mathrm{wt} / \mathrm{m}^{2}$ ). 
The copepod developmental scale has been discretized here into 5 stages, corresponding approximately to eggs, nauplii, copepodite stages I to IV, the overwintering stage $\mathrm{V}$, and egg-laying adults. Development rate during each interval is calculated as $\left.1 / t_{D} * A(D)\right)$. When water temperature is below $0^{\circ} \mathrm{C}$, or sea ice covers the model ocean (as described in the physics section), thus greatly reducing the light, primary production is assumed inadequate to support zooplankton growth, and non-overwintering stages die at the rate of $5 \%$ per day. The development rate at the upper weight boundary represents an additional ageing mortality for the adult copepods. In addition, of course, all zooplankton are subject to predation by the capelin larvae and adults, as described earlier. Equilibrium distributions of copepods in the absence of predation are shown in Fig. 17.

The krill population is modeled as a single agglomerated group of $0.1 \mathrm{gm}$ per organism, an average value estimated from Lund (1981) and Falk-Petersen (1979), Population growth occurs at the constant rate of $0 \cdot 3$ individuals per $\mathrm{m}^{2}$ per day. giving an annual production rate of about $1 \mathrm{gm} \mathrm{C} / \mathrm{m}^{2} /$ year, or $10 \%$ of the estimated total zooplankton production (Wiborg 1954). This constant recruitment rate is used because of the relatively long life span of the Euphasids (circa 2 years), and the long reproductive periods. Although densities of krill up to $15 \mathrm{~kg} / \mathrm{m}^{3}$ have been observed (Ibid.), this is certainly a localized phenomenon which cannot be modeled without a spatial patchiness parameterization. Lacking this, the maximum concentration of krill averaged over a grid cell is set at $2.5 \mathrm{~kg} / \mathrm{m}^{2}$. Figure 18 shows the equilibrium distribution of krill resulting from these assumptions.

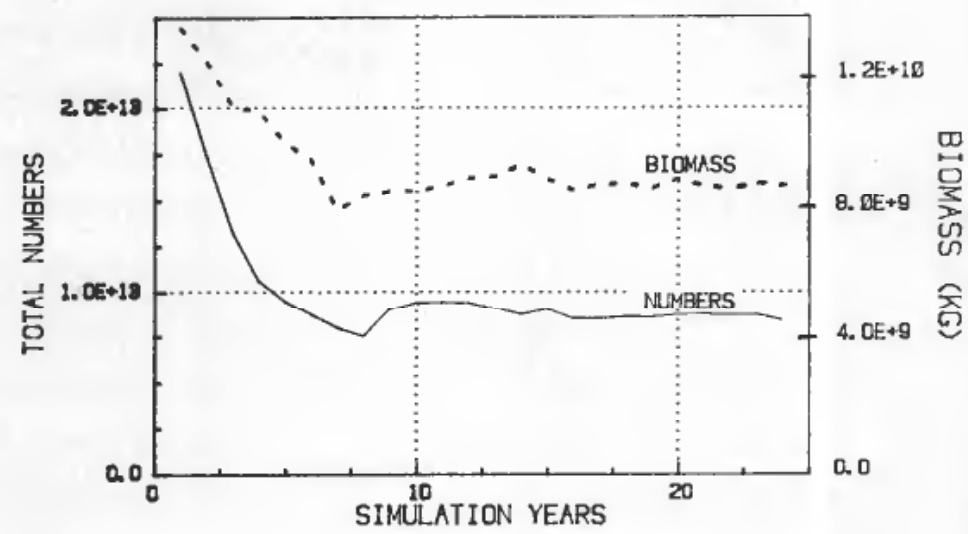

Figure 18. Total numbers and biomass of the Barents Sea capelin population as simulated over 24 years.

5. Explanation and numerical methods

For every population or subpopulation (e.g. larval capelin), there is a partial differential transport equation to be solved, of the general form

$$
\frac{\partial F}{\partial t}+\nabla^{*}\left(F v^{*}\right)+\nabla^{*} k \nabla^{*} F=\text { sources of } F-\text { sinks of } F
$$

In words, the local change plus the transport plus the diffusion are balanced by local sources and sinks of the transported constituent $F$. The number of elements in the 
gradient operator $\nabla^{*}$ and the transport rate vector $v^{*}$ is equal to the number of dimensions or continuous properties in the simulation space. In the physical realm, $k$ represents the turbulent diffusion rate. The analogous idea in biological dimensions can be taken as a reflection of uncertainties associated with calculated growth and development rates. The diffusion term has been omitted from computations in the model for two reasons. In the first place, the preliminary nature of the model renders the quantitative assessment of uncertainties impossible until some measure of validity relative to empirical data is. achieved. Secondly, the simple integration schemes used here result in numerical diffusion which, if unchecked, would certainly exceed any realistic rates. The problem is therefore the control of diffusion rather than its implementation. There is no artificial smoothing, as used for example by Laevastu, Favorite, and Larkins (1979), although the solution of the transport terms follows the same first order 'upstream' gradient advective approximation.

Let subscripts $I, J, K$ and $L$ refer to discretized intervals along the $x, y$, age and length axes respectively. Then the local rate of change within a cell is given by the sum of the transports into the cell minus the transports out, in the absence of sources and sinks. With the transport rates defined at the cell boundries, the influx during a time interval $\Delta t$ is approximated by

$$
\begin{aligned}
\Delta_{1} F_{I, J, K, L}= & {\left[u_{I, J} F_{I, J-1, K, L} \frac{\delta^{+}}{\Delta x}+u_{I, J+1} F_{I, J+1, K, L} \frac{\delta^{-}}{\Delta x}\right.} \\
& +v_{I, J} F_{I-1, J, K, L} \frac{\delta^{+}}{\Delta y}+v_{I+1, J} F_{I+1, J, K, L} \frac{\delta^{-}}{\Delta y} \\
& +v_{a(I, J, K-1, L)} F_{I, J, K-1, L} \frac{1}{\Delta a} \\
& \left.+v_{l(I, J, K, L)} F_{I, J, K, L-1)} \frac{\delta^{+}}{\Delta l}+v_{l(I, J, K, L+1)} F_{I, J, K, L+1} \frac{\delta^{-}}{\Delta l}\right] \Delta t
\end{aligned}
$$

in which

$$
\begin{aligned}
\delta^{+} & =1 \text { if the associated rate is positive, } 0 \text { otherwise } \\
\delta^{-} & =1 \text { if the associated rate is negative, } 0 \text { otherwise } \\
v_{a} & =\text { ageing or development rate } \\
v_{l} & =\text { length, growth rate, and } \\
\Delta x & , \Delta y, \Delta l, \Delta a \text { are discretized interval sizes }
\end{aligned}
$$

The net efflux is

$$
\begin{aligned}
& \Delta_{2} F_{I, J, K, L}=\left[u_{I, J} \frac{\delta^{-}}{\Delta x}+u_{I, J+1} \frac{\delta^{+}}{\Delta x}+v_{I, J} \frac{\delta^{-}}{\Delta y}+v_{I+1, J} \frac{\delta^{+}}{\Delta y}\right. \\
& \left.+v_{a(I, J, K, L)} \frac{1}{\Delta a}+v_{l(I, J, K, L)} \frac{\delta^{-}}{\Delta l}+v_{l(I, J, K, L+1)} \frac{\delta^{+}}{\Delta l}\right] F_{I, J, K, L^{\Delta t}}
\end{aligned}
$$

Unlike transport by incompressible fluids, the zero divergence criterion does not in general apply to biological processes. Larval fish are observed to actually shrink in 
length under starvation conditions (Blaxter 1969), so that transport can be positive into a discretized length cell from above (longer larvae shrinking) and below (shorter larvae growing). Because longer larvae need larger food items (or more smaller food items) than shorter larvae per unit time, such situations do arise in model simulations. Other examples of non-zero divergence arise in the physical domain due to active swimming, as is apparent in Fig. 23.

By storing values at the present timestep in the computer while all values at the next step are being calculated, an equation of the form of (5.1) can be solved rapidly, such that mass (or number) is conserved. The first order advective approximation represented by (5.2) and (5.3) is stable for

$$
\Delta t \leqslant \frac{1}{\sum\left(\frac{v_{i}}{\Delta x_{i}}\right)_{\max }}
$$

This means that $t$ must be selected less than the inverse of the sum (over all model dimensions) of the maximum ratios of transport velocities to discretized interval sizes. Since uncertainties in the parameterizations of biological processes (e.g. the larval-zooplankton interactions on scales of $1 \mathrm{~m}$ ) are critical to the actual dynamics of the population, the attainment of great numerical accuracy in the transport approximations is superfluous. If the terms of (5.1) are solved one at a time, then the timestep restriction is relaxed to

$$
\Delta t \leqslant \min \left(\Delta x_{i} / \Delta v_{i}\right)
$$

In fact, the physical advective terms $\left(u \frac{\partial F}{\partial x}+v \frac{\partial F}{\partial y}\right)$ are solved simultaneously where

$$
\Delta t \leqslant \min \left[\Delta x / 2 u_{\max }, \Delta y / 2 v_{\max }\right]
$$

gives a maximum timestep on the order of 2 days. When the swimming ability of the fish is included, the maximum possible timestep falls to about 1 day. When limitations in all dimensions (egg development, larval and adult growth and ageing, zooplankton development) have been considered, the above consideration is found to govern. Computation of the ageing term in (5.2) and (5.3) is obviated by performing an advance of all organisms along the age axis at time intervals equal to the interval of discretization. This also eliminates diffusion problems in the age dimension. This approach is not possible in the egg domain, since the development rate is a function of temperature. The implementation of a logarithmic transformation along the ageing axis, to facilitate the conjunction of the larval and adult domains, will also require the calculation of the ageing term.

Numerical diffusion is controlled in two ways. In the two dimensional physical domain, noting that the adult population size is $\mathrm{O}\left[10^{12}\right]$, that single accuracy computational precision is perhaps 1 part in $10^{6}$, and that calculations performed in cells with fewer fish than $10^{6}$ therefore represent wasted time, it is expedient to place a lower limit on the number of fish allowable in a grid cell. At the end of a timestep, the physical field is accordingly searched for cells containing fewer than a threshold value, $10^{7}$ being used here. When such a cell is found, the 8 surrounding physical 
cells are searched for that with the maximum density to which the fish from the low density cell are added. This introduces only small errors in the resulting distributions, on the order of 1 part in $10^{4}$, and strictly controls numerical diffusion. One problem with the procedure is that an isolated concentration just above the threshold value may not be subject to physical advection.

Numerical diffusion in the length domain is controlled by noting that the first order approximation used here neglects terms of higher order in the Taylor expansion. A simple computation shows that if length growth rates at length intervals $L+1$ and $L+2$ are positive for two successive timesteps, and transport rates in other dimensions are small, then the numerical diffusion error in cell $L+2$ is approximately

$$
F_{L, t} * v_{l(L), t} * v_{l(L+1), t+1} *\left(\frac{\Delta t}{\Delta l}\right)^{2}
$$

Since other transport rates are often of about the same magnitude, implementation of this correction requires that it be used as an upper bound. If the growth rates change sign or are of opposite sign, the correction becomes invalid and must be bypassed.

Although somewhat primitive, this numerical scheme appears to function satisfactorily, as demonstrated in $\S 6$.

\section{Population dynamics}

Numerous tests of the capelin population model in the context of the simulated environment described above have been performed. Some of these will be discussed briefly here, both because they induced changes in the model, and because they revealed certain system attributes which were not obvious at first. Model runs, typically initialized with an arbitrary population on the order of $10^{13}$ adults, with numbers decaying exponentially in both age and length dimensions, near the centre of the model ocean, without predators, at first resulted in an empty ocean (population size zero) after 6 years' simulation. The youngest fish had then been transported out of the model through the upper adult age boundary, or had died during spawning. The problem proved to be that the mature capelin were arriving at the spawning grounds near the end of the spawning season (circa May 1), so that when the larvae hatched out perhaps 40 days later, the production of calanus eggs had decreased such that none of the larvae were surviving. Although one must be cautious in drawing conclusions from such a simplified system, this suggests that a summer spawning population on the Finnmark coast may not be a self-supporting stock, but represents anomalous maturation of adults. This would be in agreement with the intermittency of observations of this late spawning behaviour (Prokhorov 1965). Improvements in the system components will allow more accurate tests of this hypothesis in the future. That factors (e.g. climate) causing anomalous physiological development (late maturation) in adults can play a key role in recruitment success due to late spawning and subsequently inadequate larval food supplies has been suspected by fisheries scientists for decades. It is encouraging that we are beginning to be able to test such complex hypotheses, and hopefully to eventually uncover more of the processes important in determining fish population dynamics, processes that underly the failure of simple stock-recruitment relationships to predict recruitment success.

The distribution of the sexual (light seeking) hormone was then adjusted 60 days back in time, to the position shown in Fig. 11. 
Further experiments with the model confirmed the conclusion that a cod population on the order of $10^{9} \mathrm{~kg}$, consuming $0.007 \mathrm{~kg}$ capelin $/ \mathrm{kg} / \mathrm{day}$, plus a population of mammals between $10^{8}$ and $10^{9} \mathrm{~kg}$, consuming $0.025 \mathrm{~kg} / \mathrm{kg} / \mathrm{day}$, and a fishery extracting $10^{9} \mathrm{~kg}$ per year from a fish population of $8 * 10^{9} \mathrm{~kg}$, will leave very few fish in the ocean after a short while. Corrective options include increasing the density dependence of predation, increasing the probabilities of larval capelin survival though higher zooplankton concentations or a lower starvation boundary, decreasing the cod and/or marine mammal predation rates, or decreasing the population sizes of these predators. Because of the preliminary nature of the model system as a whole, it was decided to simply decrease the slope of the density dependent predation curve (Fig. 9) by a factor of 10 . This effectively halves the predation rate at typical levels of $10^{8}$ capelin/grid cell. In addition, the physical field has been represented by a coarser $12 \times 12$ grid system to reduce run time.

The following simulation results from a model run incorporating the above changes. Figure 8 shows the decline of both stock numbers and biomass from their original estimated levels to their near-equilibrium values after 24 simulation years. As is typical of age-length-weight growth models, the biomass dynamics follow a damped form of the numbers dynamics. Because growth in the present model is density dependent (fewer fish mean more zooplankton per fish), the decline of the biomass curve ceases one year earlier than that of the numbers curve. Figure 19 shows the distribution of numbers by age group throughout the simulation. Both these figures suggest that the system is near its equilibrium level at the end of the simulation.

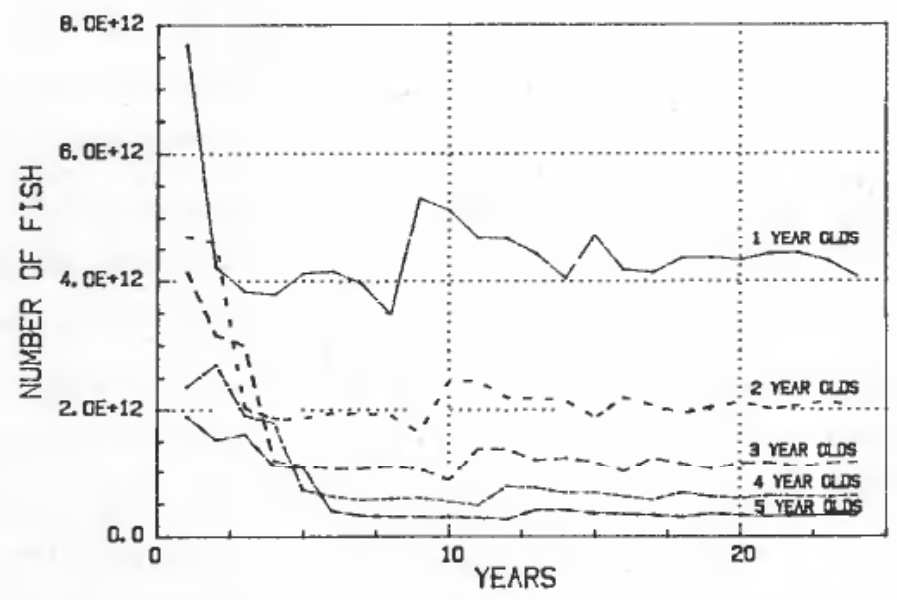

Figure 19. Numbers of capelin by age group.

Figures $20(a-x)$ show 24 seasonal distributions of a year class in physical space. Land masses are located as shown in Fig. 3. The contour intervals and maximum numbers of capelin per grid cell are given in Table 2. Figure $20(a)$ shows the distribution of the 0-group at 2 to 3 months of age. The summer and autumn (Fig. $20(b, c)$ ) show a short migration to the north, with a return to the warmer, southerly waters in the winter. During their second year, the mean length is approximately $6 \mathrm{~cm}$ in the model, and the active migrations are more pronounced (Fig. $20(e-h)$ ). Because most 

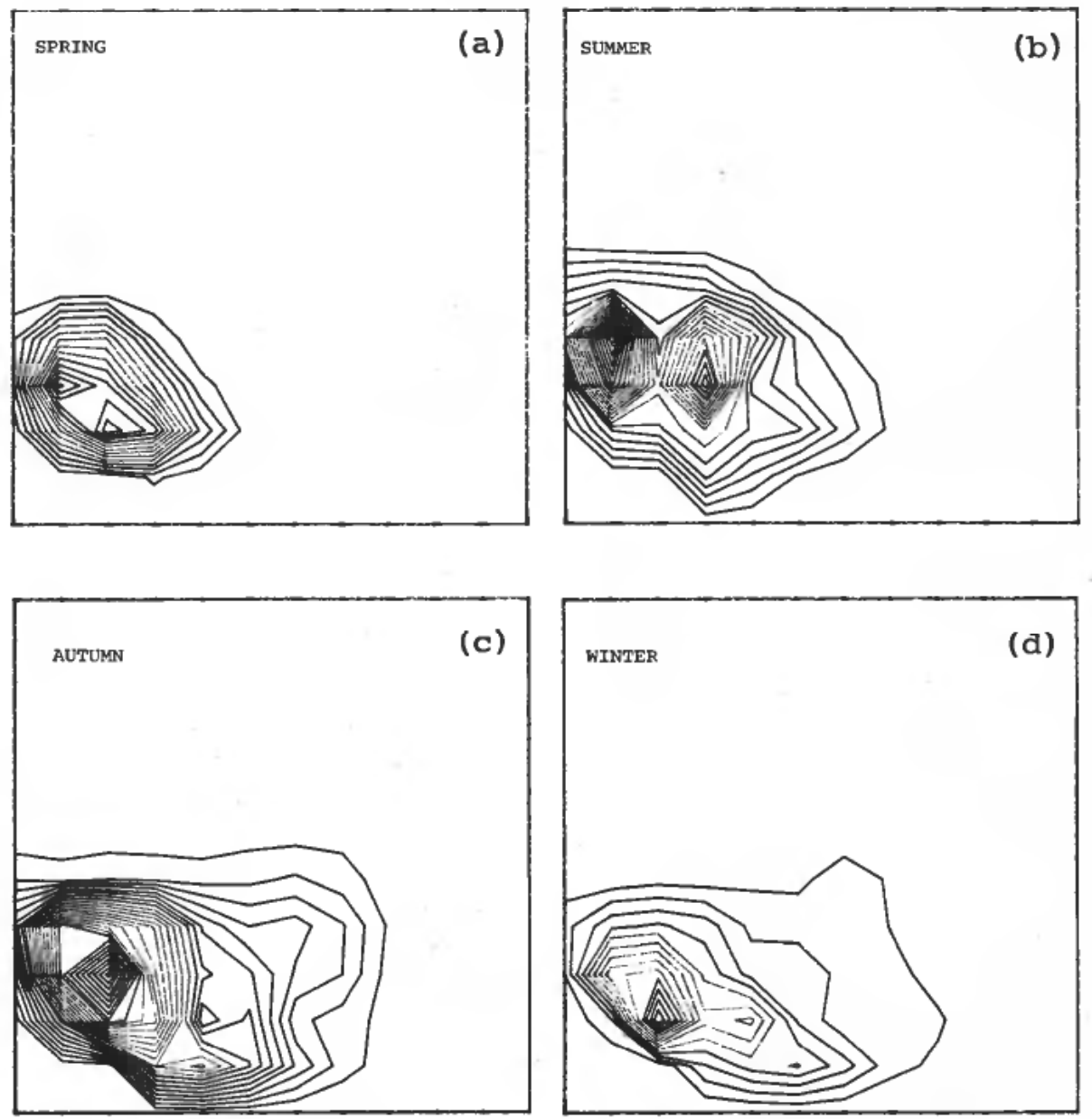

Figures $20(a-d)$. Distributions during the first year of life. Refer to Table 2 for contour intervals and maximum values.
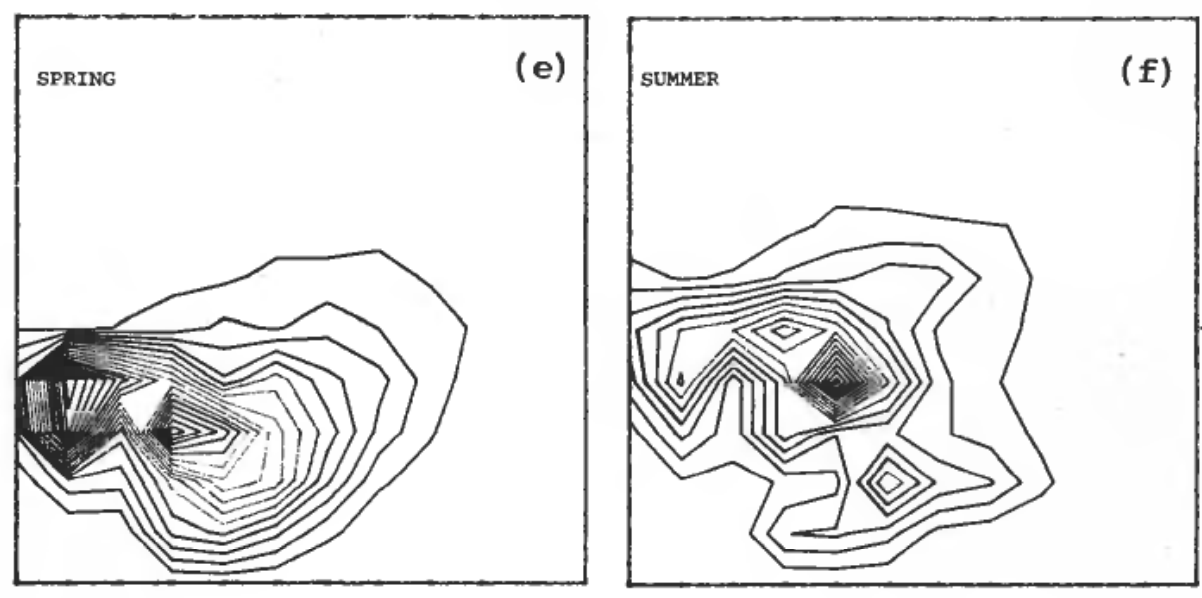

M.I.C. 


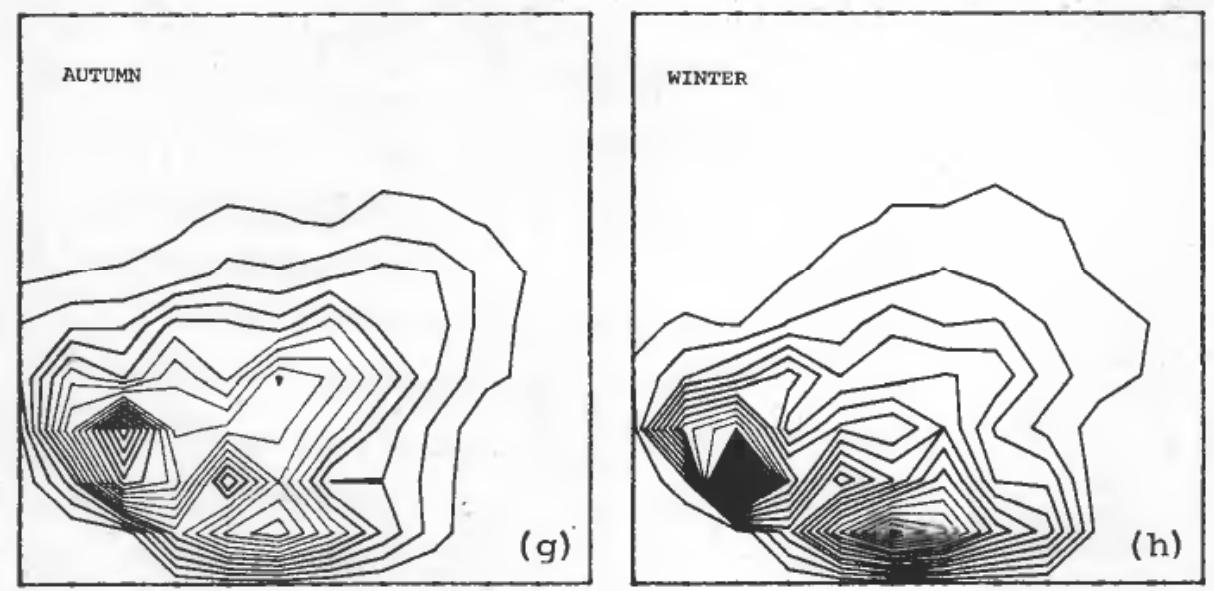

Figure $20(e-h)$. Distributions during the second year.
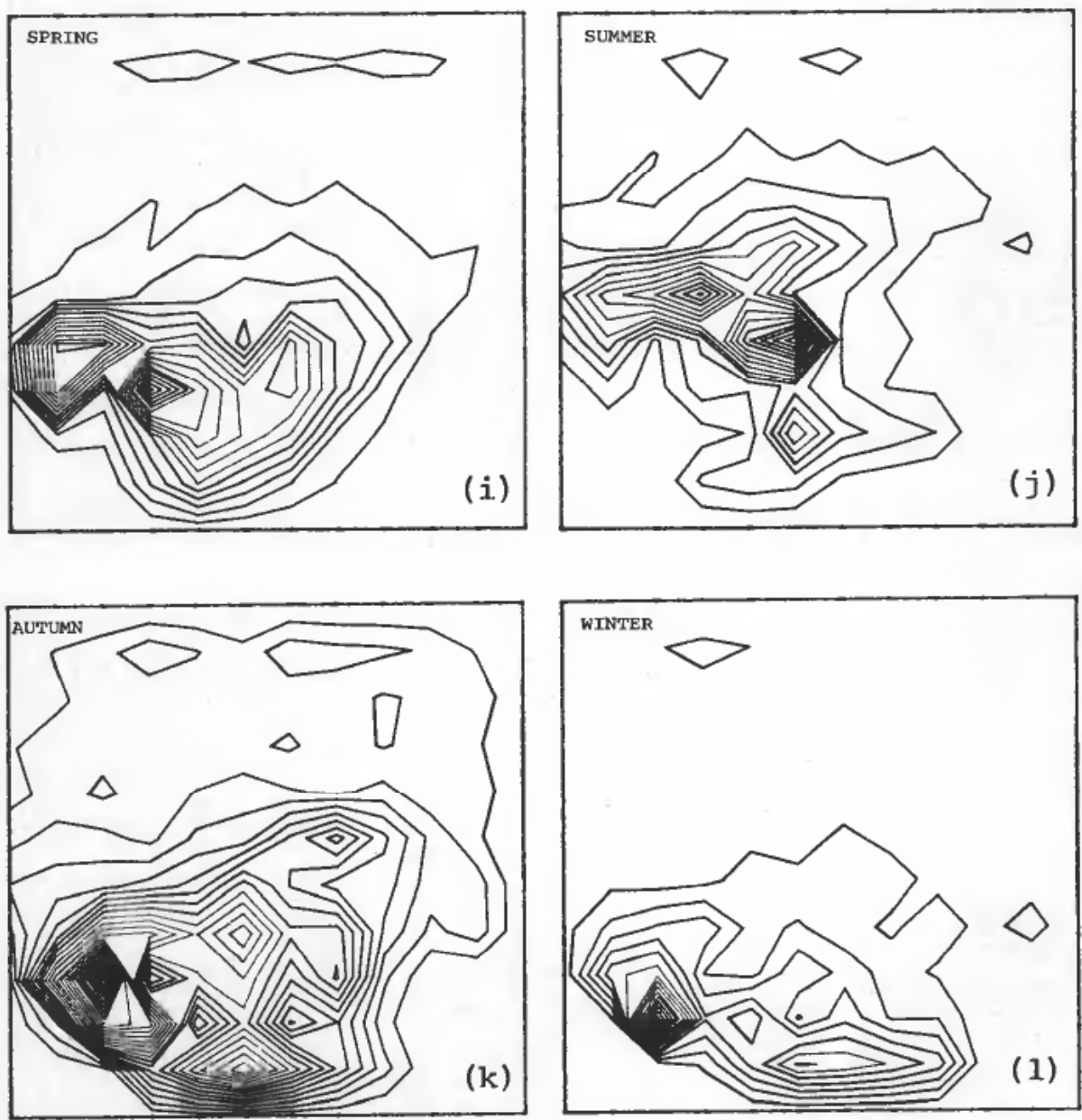

Figure $20(i-l)$. Distributions during the third year. 

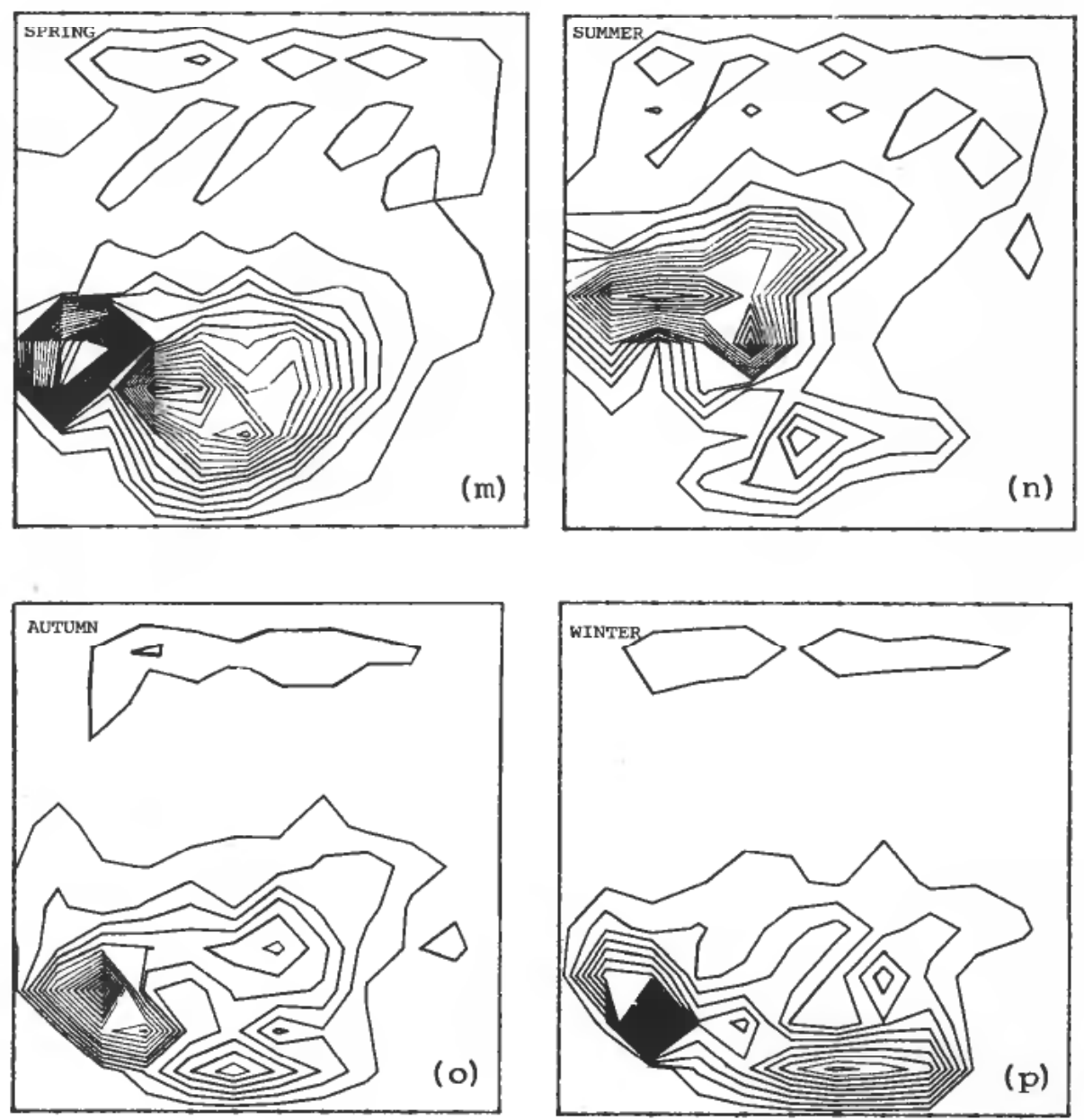

Figure $20(m-p)$. Distributions during the third year. The mature portion is concentrated north of Finnmark (lower left), and will spawn and die in the spring.
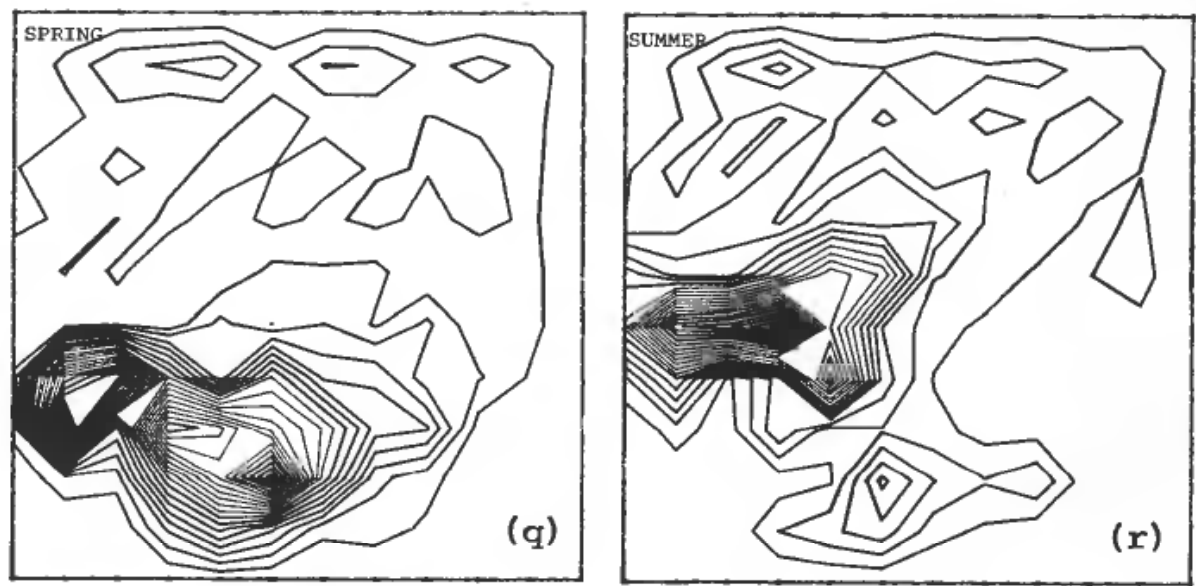

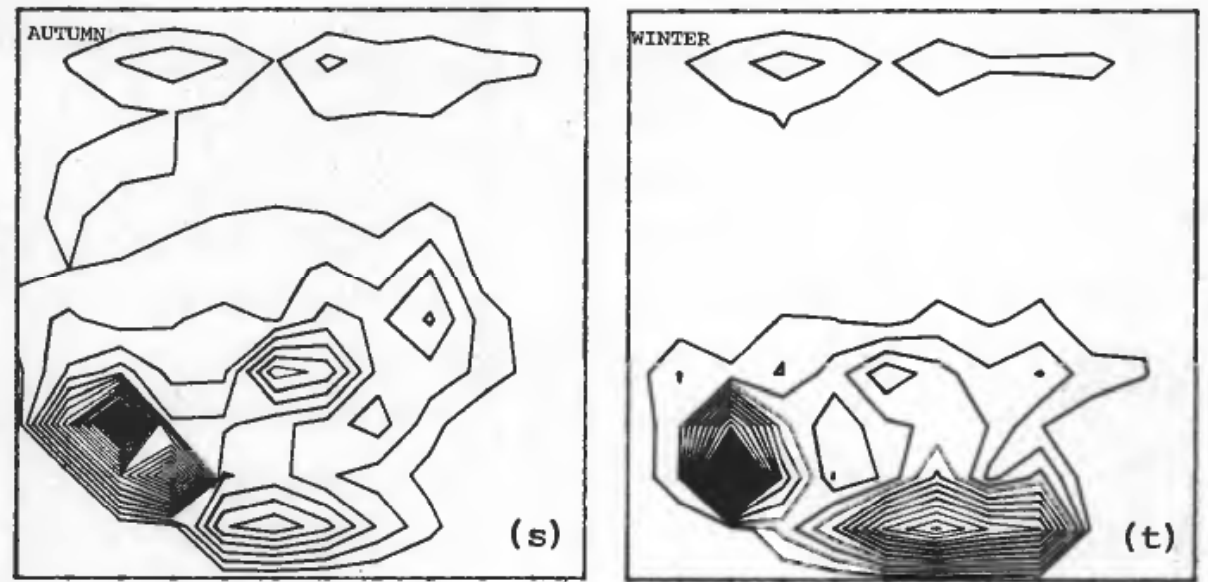

Figure $20(q-t)$. Distributions during the fourth year. These are the same fish as those making up the distribution in Fig. $20(p)$, minus those lost to spawning mortality, predation, and active or passive transport out of the system through open boundaries.
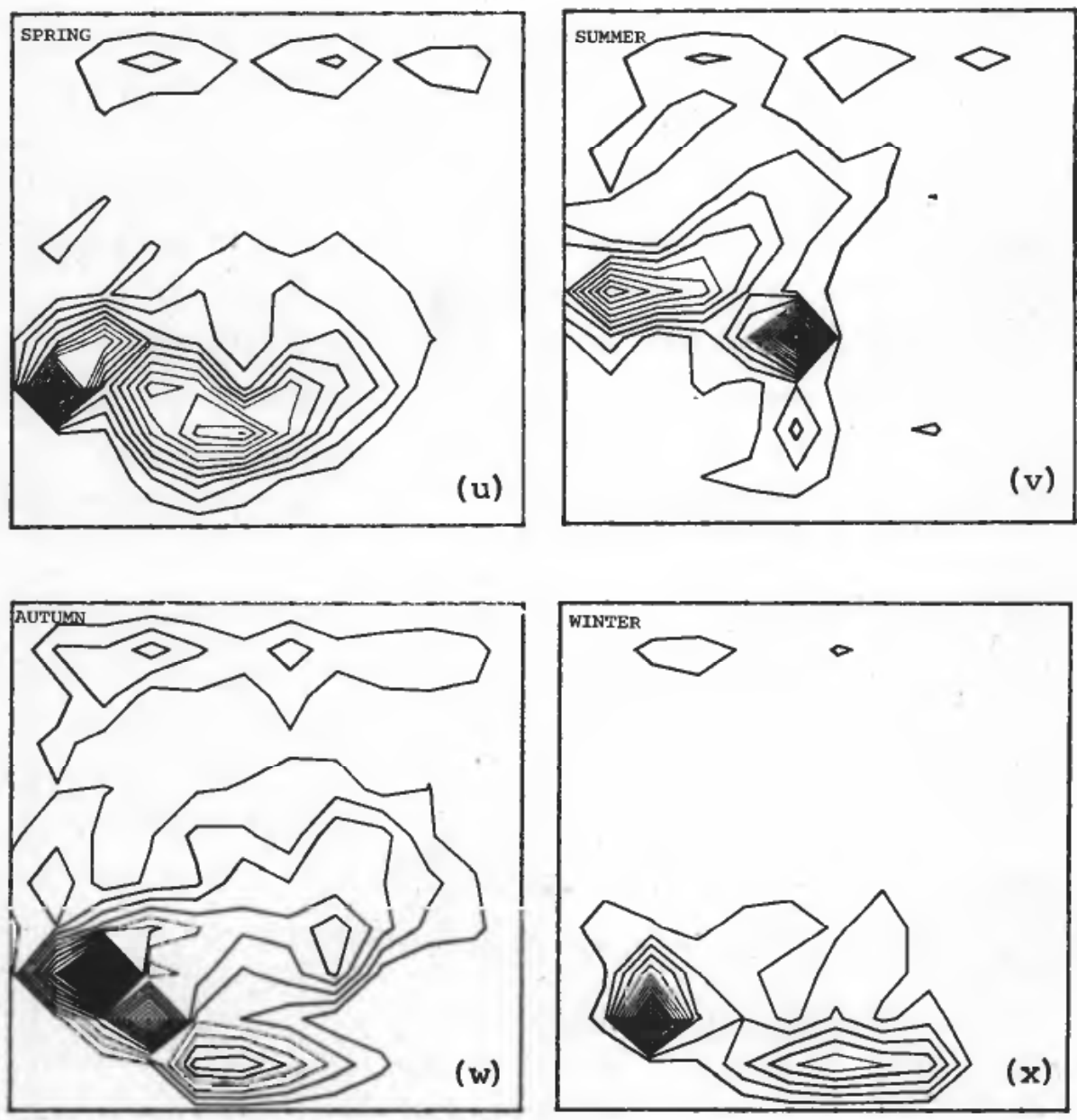

Figure $20(u-x)$. Distributions during the fifth year. 


\begin{tabular}{|c|c|c|}
\hline $\begin{array}{l}\text { Figure } \\
\text { Number }\end{array}$ & $\begin{array}{l}\text { Contour } \\
\text { Interval }\end{array}$ & $\underset{\text { Value }}{\text { Maximum }}$ \\
\hline $20(a)$ & $50 \cdot 0$ & $750 \cdot 0$ \\
\hline (b) & $20 \cdot 0$ & $420 \cdot 0$ \\
\hline (c) & $10 \cdot 0$ & $270 \cdot 0$ \\
\hline$(d)$ & $20 \cdot 0$ & $280 \cdot 0$ \\
\hline (e) & $10 \cdot 0$ & $180 \cdot 0$ \\
\hline$(f)$ & $10 \cdot 0$ & $160 \cdot 0$ \\
\hline$(g)$ & $5 \cdot 0$ & $85 \cdot 0$ \\
\hline (h) & $5 \cdot 0$ & $100 \cdot 0$ \\
\hline (i) & $5 \cdot 0$ & 88.0 \\
\hline (j) & $5 \cdot 0$ & $75 \cdot 0$ \\
\hline$(k)$ & $2 \cdot 0$ & $52 \cdot 0$ \\
\hline$(l)$ & $5 \cdot 0$ & $80 \cdot 0$ \\
\hline$(m)$ & $2 \cdot 0$ & $44 \cdot 0$ \\
\hline (n) & $2 \cdot 0$ & $32 \cdot 0$ \\
\hline$(o)$ & $2 \cdot 0$ & $32 \cdot 0$ \\
\hline$(p)$ & $2 \cdot 0$ & $46 \cdot 0$ \\
\hline (q) & 1.0 & $25 \cdot 0$ \\
\hline$(r)$ & 1.0 & $21 \cdot 0$ \\
\hline$(s)$ & $1 \cdot 0$ & $20 \cdot 0$ \\
\hline$(t)$ & $1 \cdot 0$ & $27 \cdot 0$ \\
\hline$(u)$ & $1 \cdot 0$ & $16 \cdot 0$ \\
\hline (v) & $1 \cdot 0$ & $14 \cdot 0$ \\
\hline$(w)$ & 0.5 & $13 \cdot 0$ \\
\hline$(x)$ & $1 \cdot 0$ & $15 \cdot 0$ \\
\hline
\end{tabular}

Table 2. Contour intervals and maximum values (numbers of capelin per grid cell $\left.\times 10^{-9}\right)$ for Fig. $20(a-x)$.

capelin in the model are located in the southern two thirds of the ocean, the concentrations of krill tend to be highest in the far north. Thus the fish that are able to swim the fastest (i.e. the longest fish) are also able to feed the best, and thus mature earlier. This northerly component of the stock includes about $1 \%$ of the capelin in the model aged 2 to 3 years (Fig. $20(i-l)$ ). During their fourth and fifth years (Fig. $20(m-t)$ ), the contributions made to the spawning stock reach maximum. During the sixth year, although a larger percentage of the age group is mature, the total contribution to the

Figure $20(a-x)$. Physical distributions of the year class entering the population as a result of spawning during spring of the 17th year of simulation. This year class is traced throughout the series, season by season, until those remaining at the end of their sixth year (i.e. they are 5+ years old) are lost to the system across the upper age boundary. Because the system is near equilibrium, each set of four seasonal 'snapshots' can also be viewed as typical for that age group, given the model formulations and parameters as described in the text. Associated contour intervals and maxima are given in Table 2. M.1.c. 


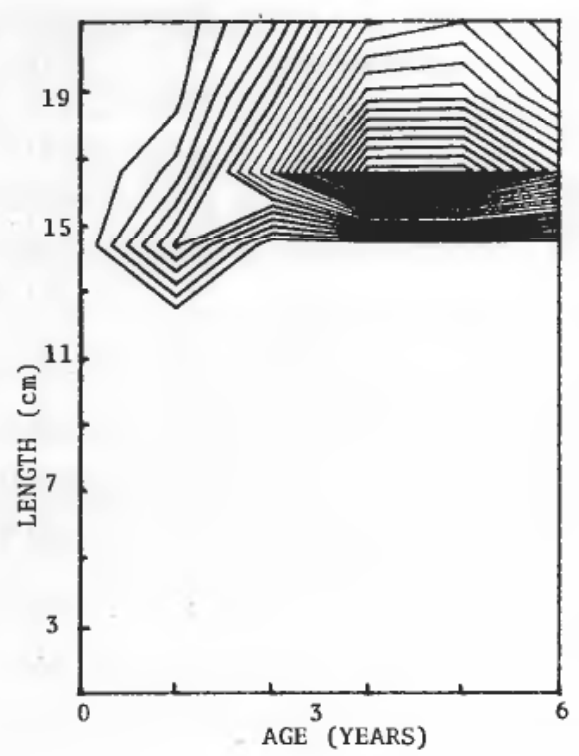

Figure 21. Age-length distribution of mature capelin on one section of the spawning grounds in early March. Maturation in the model appears to occur approximately one year later than in reality. This is attributable to slow growth rates (too many fish, too few plankton) and/or a faulty length-maturation parameterization in the model.

spawning stock decreases, since there are fewer fish of this age. This can be seen in Fig. 21, which shows the age-length distributions of capelin in a spawning grid on about March 10. The stock is composed primarily of fish in their fourth and fifth years and 15 to $19 \mathrm{~cm}$ in length. If food is made more plentiful in the model, growth rates increase, and maturation occurs earlier.

Fig. $22(a-d)$ shows typical distributions of immature capelin at various times of year. The distributions are dominated by the 0-group, especially in the spring when their numbers are high and little spatial diffusion has taken place. The separation into subgroups that occurs during the summer is a result of uneven food distributions in the model.

As mentioned earlier, the longest fish are found farthest north in the autumn, at the end of the feeding season, so it is here that the mature fish are found (Fig. $23(a)$ ). As the activity of the sexual hormone increases (Fig. $11(c)$ ) and the perceived need for food decreases, the fish tend to agglomerate more and to swim south toward the disappearing winter sun (Fig. $23(b, c)$ ). With the reappearance of the sun in the late winter and early spring, the fish are seen to converge in the warmer waters off the Finnmark coast to spawn. Fig. $24(a, b)$ shows the capelin associated with a grid cell to the north of the Finnmark coast in summer, when the longer fish are feeding in the north, and in winter, when most of the fish are again in the southern sector.

This simulation is presented primarily to demonstrate the versatility of the continuum approach to population modeling, and the potential utility of the capelin model itself as a tool for realistic management of the fishery. The model requires many improvements before it can be relied upon, and many aspects of the model are merely hypotheses employed for lack of better alternatives. With feedback from 

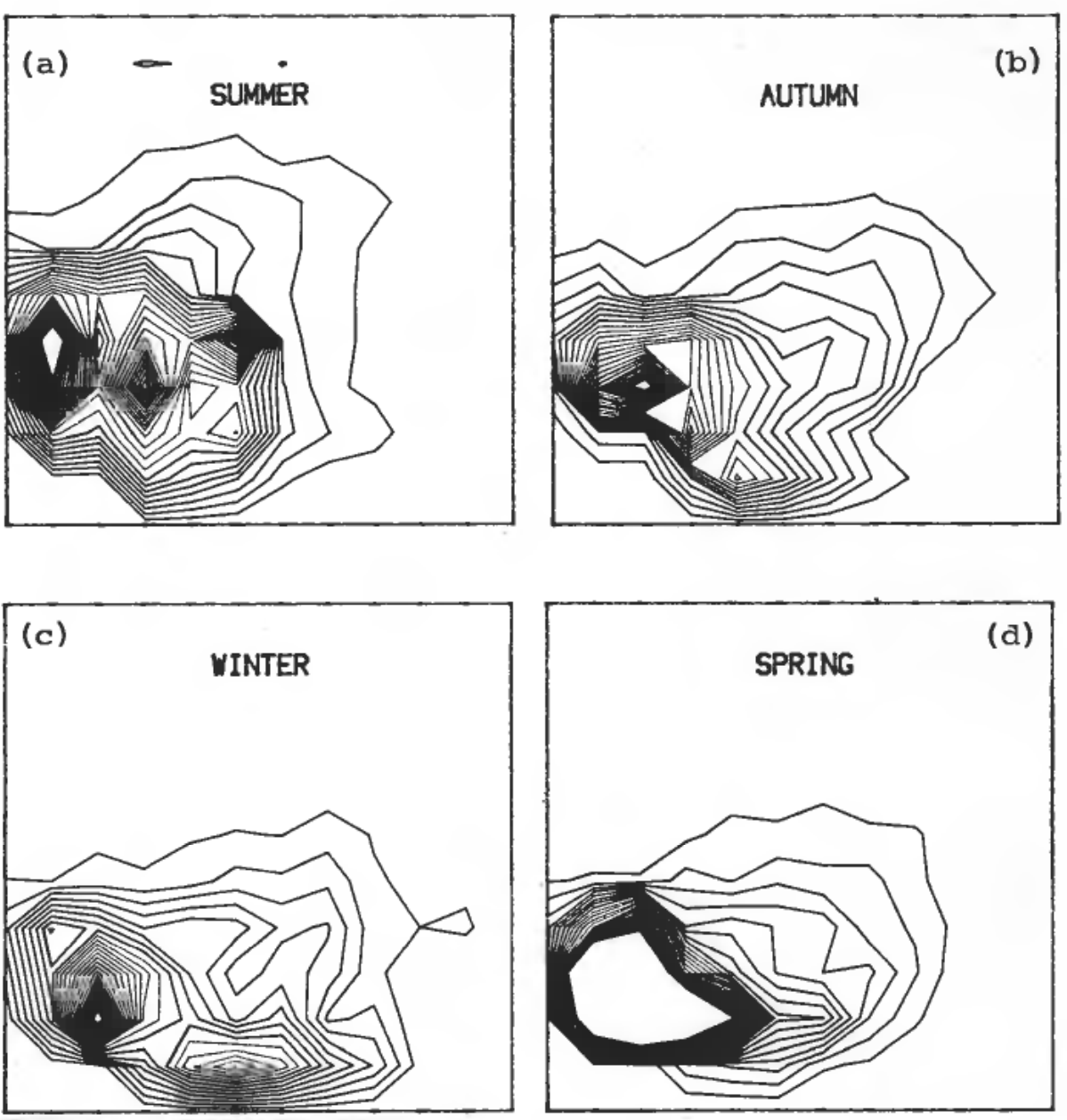

Figure $22(a-d)$. Physical distributions of immature capelin during the final simulation year. (Contour interval: $2 \cdot 0 \times 10^{10}$, maximum value shown: $5 \cdot 0 \times 10^{11}$.)

knowledgeable fisheries biologists, iterative improvements can be made, such that the model eventually becomes a working tool for stock management.

\section{Summary}

An example of a fish population model, continuous in physical, temporal, and biological dimensions, has been presented, along with a set of simple submodels providing an operational testing environment. Simulations discussed demonstrate the usefulness of the approach in evaluating relatively complex hypotheses concerning fish behaviour, ecological reasons underlying recruitment success and failure, and relationships between population size and individual growth rates.

The strength of the continuum approach to biological modeling arises from its ability to realistically represent actual phenomena without appreciably increasing data requirements. Its major drawback has been the need for large, fast computers. New technology has relieved this restriction, so that biologists are now free to adapt this theoretical basis for model construction. 

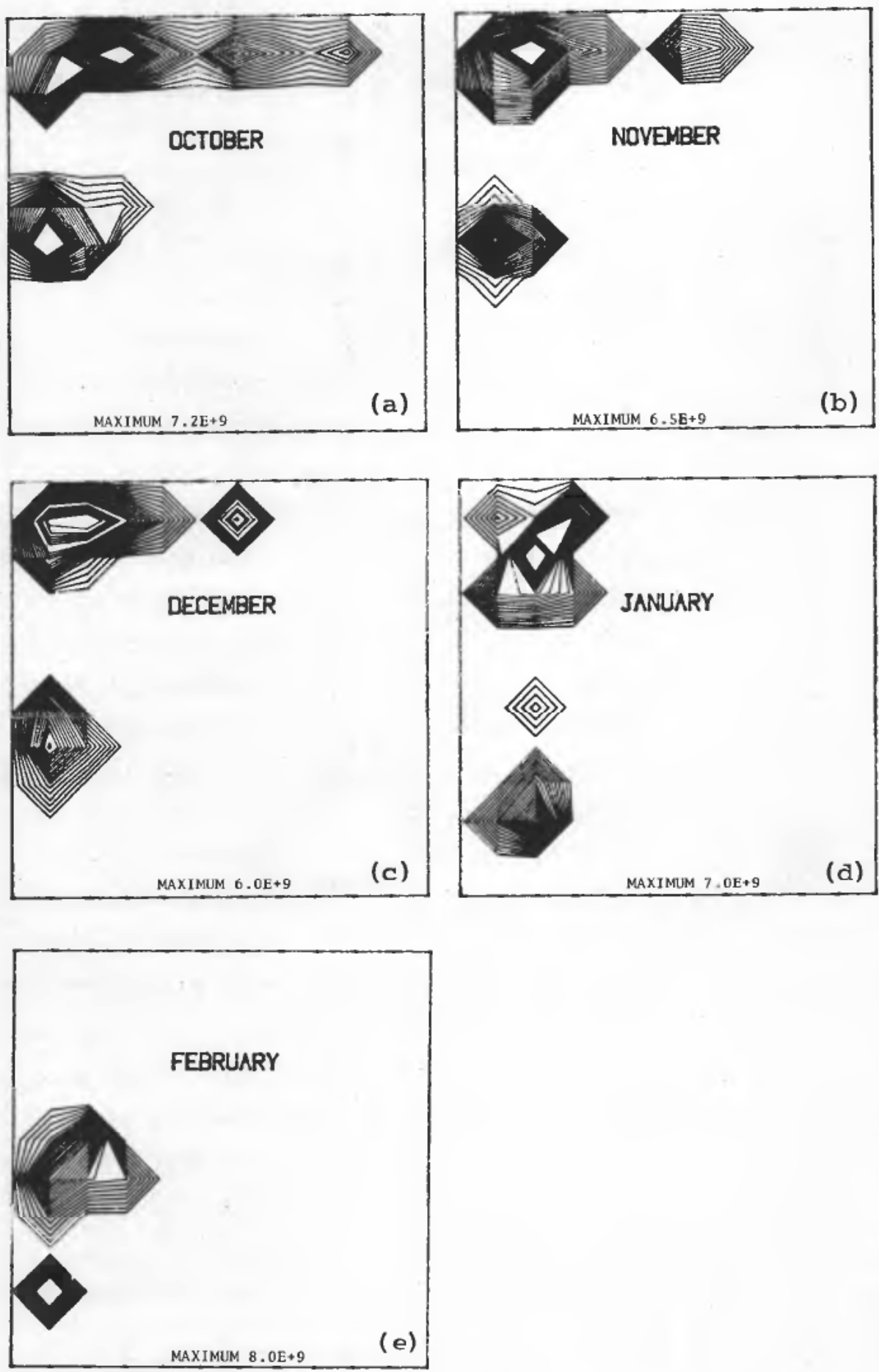

Figure $23(a-e)$. Five simulated monthly distributions of maturing or mature capelin in the Barents Sea. The total number of fish shown decreases by about $10 \%$ through the series due to transport out the western boundary. Occasionally, mature fish from the northwest corner will arrive at the spawning grounds so late (e.g. May) that none of the resulting larvae have sufficient food to survive. These fish also sometimes spawn off the coast of Novaya Zemlya if the model permits. In neither case is the pattern biologically selfsustaining (contour interval: $2 \cdot \emptyset \times 10^{8}$ ). 

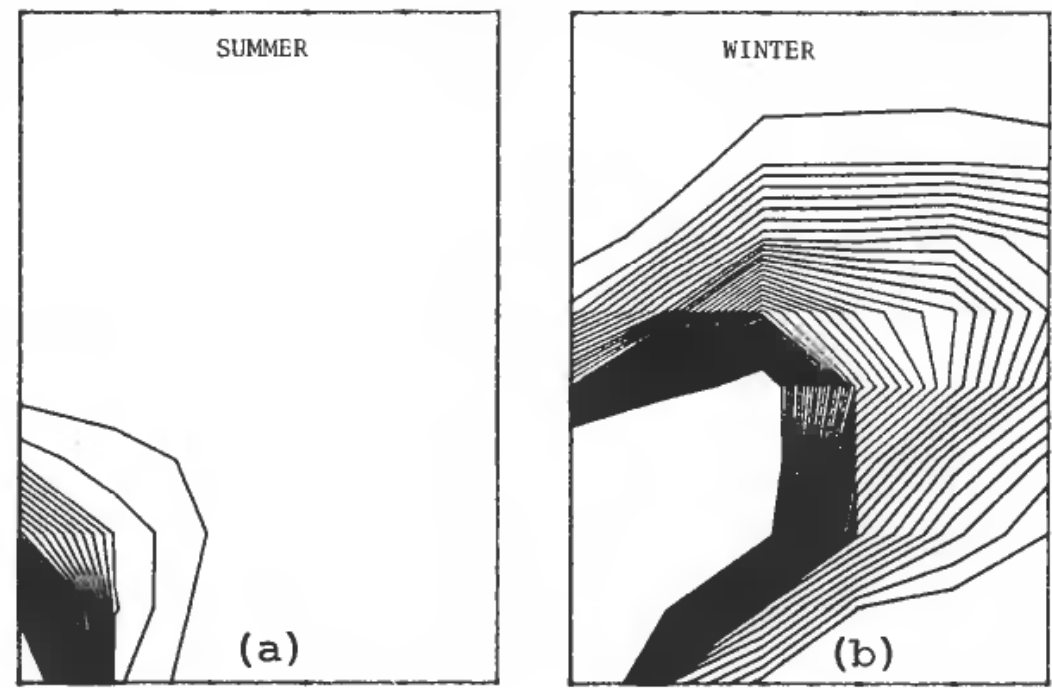

Figure $24(a-b)$. Age-length distributions off the coast of Finnmark in summer and winter. Axes are scaled as in Fig. 21. (Contour interval 5.0E +8 ; maximum value shown: $2 \cdot 0 \mathrm{E}+10$.)

\section{ACKNOWLEDGEMENTS}

This work has been sponsored by the Royal Norwegian Council for Scientific and Industrial Research and the Norwegian Fisheries Research Council through the research programme HAVBIOMODELLER (OCEAN-BIO-MODELS).

The authors wish to thank Sigurd Tjelmeland, Are Dommasnes, and Johannes Hamre at the Institute of Marine Research, Bergen, and Kjell Olsen and Per Grotnes, University of Tromsø, for many constructive discussions and suggestions. Thanks also to Eva Amdahl, who typed the manuscript.

\section{REFERENCES}

Andersen, K. P., and Ursin, E. (1977). A multi-species extension of the Beverton and Holt theory of fishing, with accounts of phosphorous circulation and primary production. Meddelser fra Danmarks Fiskeri og Havundersegelser, 7, 319-434.

ANONYMOUS (1981). Ressursoversikt. Fisken og Havet (Særnummer 1), 1-52.

ANONYMOUS (1979). Resource overview for 1979-1980 (Ressursoversikt for 1979-1980). Fisken og Havet, Havforskningsinstituttet, Bergen, Særnummer 1.

ANONYMOUS (1975). Investigating on capelin and cod in the Barents Sea during the winter of 1975. Fiskets gang, 5, 69-73.

ANONYmous (1958). Oceanographic Atlas of the Polar Seas. Part II: ARCTIC (U.S. Navy Hydrographic Office, Washington D.C.).

ATKINSON, D. G., and CARSCADDEN, J. E. (1979). Biological characteristics of inshore capelin, Mallotus Villosus (Müller), June-July 1977. Fish. Mar. Serv. Tech. Rep. 881: iv +18 p. Dept. of Fisheries Envmnt Canada.

BAKKe, S., and BJøRKE, H. (1973). Diving observations on Barents Sea capelin at the spawning ground off northern Norway. Fisk. Dir. Sea. Hawllanders, 16, 140-147.

BALCHEN, J. G. (1980). Modeling and identification of marine ecological systems with applications in measurement of fish resources and planning of fisheries operations, Modeling, Ident., and Control, 1, 67-68.

BALCHEN, J. G. (1979). Modeling, prediction and control of fish behavior, pp. 99-146 in Control and Dynamic Systems, edited by C. T. Leondes (Academic Press, New York). 
Balchen, J. G. (1976). Principles of migration in fishes. SINTEF Technical report nr. 81, May 1976, 33 pp.

BeltestAD, A. K., NAKKen, O., and Smedstad, O. (1975). Investigations in the diel vertical migration of O-group fish in the Barents Sea. Fisk. Sir. Skr. Ser. Havllnders, 16, 229-244.

Benjaminsen, Terje (1979). Pup production and sustainable yield of white sea harp seals. Fisk. Dir. Skr. Sea. Havunders., 16, 551-559.

BERNTSEN, HANS, et al. (1981). Efficient numerical simulation of ocean hydrodynamics by a splitting procedure. Modeling, Indent., and Control, 2, 181-199.

VON BERTALANFFY, L. (1938). A quantitative theory of organic growth laws (Inquiries on Growth Laws II). Human Biology, 10, 181-213.

BeYer, J. E., and LAurence, G. C. (1979). Modelling growth and mortality of larval herring (Clupea harengus), Early Life History Symposium, Woods Hole, Mass./M:6.

BJøRKE, H. (1976). Some preliminary results on food and feeding of young capelin larvae. ICES CM. 1976/H: 37, Pelagic Fish (Northern) Committee.

BJøRKe, J., GJøSÆTER, J., and SÆTRE, R. (1972). Investigations at the spawning grounds of capelin in 1972 (in Norwegian w/Engl. abstract). Fiskets Gang, 36, 710-716.

Blaxter, J. H. (1969 a). Development: eggs and larvae. Pp. 178-252 in Fish Physiology, Vol. III, edited by W. S. Hoar and D. J. Randall (Academic Press, New York).

Blaxter, J. H. S. (1969 b). Swimming speeds of fish. FAO Fish. Rep. 62, Vol. 2, 69-100.

BlaXter, J., and Staines, M. (1971). Food searching in marine fish larvae, 4th European Biology Symposium, edited by J. Crisp (Comb. Univ. Press), pp. 467-485.

Blaxter, J., and HemPel, G. (1963). The influence of egg size on herring larvae. J. Cons. Int. Expl. Mer., 28, 211-140.

BLINDHEIM, J., and MonSTAD, T. (1972). The spawning migration of capelin in 1972. Fiskets gang, (22), 519-524.

Christensen, I., and Rørvik, C. J. (1980). Analysis of markings and recaptures of minke whales in the Barents Sea 1974-1979. Inst. Marine Research, Bergen SC/32/Mi 6.

Christensen, 1., and Rørvik, C. J. (1981). Availability of minke whales in the Barents Sea and adjacent waters. Inst. Marine Research, Bergen SC/32/Mi 7.

DAAN, N. (1979). Comparison of estimates of egg production of the Southern Bight cod stock from plankton surveys and market statistics. Mimeo. 28 pp., ICES, Early Life History Symposium, Woods Hole, Mass.

Dal.en, J., and Dommasnes, A. (1974). Loddeundersøkelser i Barentshavet i mai-juni 1974. Sartrykk av Fiskets Gang, Nr. 38, 669-673.

Dommasnes, A. (1978). Survival of tagged Barents Sea capelin (Mallotus villosus, Müller) and estimates of the 1973, 1974 and 1975 spawning stocks from tag returns. Fisk. Dir. Skr. Ser. Havunders., 16, 339-358.

Dommasnes, A., Midttun, L., and Monstad, T. (1979). Capelin investigations in the Barents Sea During the winter 1978. Fiskens Hav., (1), 1-16.

Dommasnes, A., and Olsen, K. (1974). Capelin investigations in the Barents Sea in November-December 1973. Fiskets Gang, nr. 13, 257-261.

Dragesund, O., Guøsater, J., and Monstad, T. (1973). Estimates of stock size and reproduction of the Barents Sea capelin 1970-1972. Fisk. Dir. Havunders., 16, 105-139.

Dragesund, O. (ed.) (1970). International 0-group fish surveys in the Barents Sea 1965-1968. ICES Cooperative Research Report. Series A, No. 18.

EBenHöH, W. (1980). A model of the dynamics of plankton patchiness. Modeling, Indent., and Control, 1, 69-81.

Ehrlich, K., Bl.axter, J., and Pemberton, R. (1976). Morphological and histological changes during the growth and starvation of herring and plaice larvae. Mar. Biol., 35, 105-118.

ERVIK, LeIf K., and Roman, R. C. (1975). The capelin population and exploration-a dynamic analysis. Chr. Michelsens Inst. Report 75056-1, Bergen, Norway, 212 pp.

Falk-Petersen, S. (1979). Populasjonsdynamikk, Vektstrategi, Protein- og Lipidinnhold hos Krillartene Thyanoessa Intermis (Krøyer), Thysanoessa Raschii (M. Sars) and Meganyctiplanes Norwegica (M. Sars). Fra Balsfjorden Nord-Norge. Ph.D. Thesis, University of Tromsø (in Norwegian), $121 \mathrm{pp}$.

FranK, J. T., and LegGeTT, W. C. (1981). Wind regulation of emergence times and early larval survival in capelin (Mallotus villosus). Can. J. Fish Quat. Sci., 38, 215-228. 
FriĐgeIRsSon, Eyjolfuer (1976). Observations on spawning behavior and embryonic development of the Icelandic capelin. Rit Fiskideildan, 5, $36 \mathrm{pp}$.

GALL, G. (1974). Influence of size of eggs and age of females on hatchability and growth in rainbow trout. Calif. Fish and Game J., (1), 26-35.

GJøSfter, J., and MonSTAD, T. (1973). Fecundity and egg size of spring spawning Barents Sea capelin. Fisk. Dir. Havunders., 16, 98-104.

GJøSÆTER, J. (1972). Recruitment of the Barents Sea capelin 1951-1961, ICES C.M. 1972/H: 24.

Gjøsfeter, J., Midttun, L., Monstad, T., Nakken, O., Smedstad, O., Słtre, R., and UlLtANG, Ø. (1972). Investigations of fish distribution and abundance in the Barents Sea and off Spitsbergen in August-September 1972. Fiskets Gang, 51, 1010-1021.

Gulland, J. A. (1964). Survival of the youngest stages of fish and its relation to year class strength. ICNAF Spec. Publ. 6, pp. 363-372.

HAMre, J., and MonstAD, T. (1980) (1979). Capelin investigations in the Barents sea during winter 1980. Fisken Hav., (5), 3-22 (in 1979). Fisken Hav., (4), 3-17.

HAMre, J., and SeTRE, R. (1976). The spawning migration of capelin during the winter of 1976. Fisken Hav., (2), 43-51.

Harden Jones, F. R. (1968). Fish Migration (Edward Arnold, London), 325 pp.

HARVEY, J. (1964). Factors Affecting Water Temperature in the Seas North of Norway. ICNAF Spec. Publ. 6, 869-879.

Himmelblau, D. M., and Bischoff, K. B. (1968). Process Analysis and Simulation in Deterministic Systems (J. Wiley \& Sons, New York), 348 pp.

HJORT, JoHAN (1914). Fluctuations in the Great Fisheries in Northern Europe. Viewed in the Light of Biological Research. Com. Perm. Int. Exp. Mer. Rapp. et Proc. Verb., 20, 228 pp., 137 figs.

Hocharka, P. W., and Somers, G. N. (1971). Biochemical adaptations to the environment. Chapter 2, pp. 100-156 in Fish Physiology, Vol. VI, edited by W. S. Hoar and D. J. Randall (Academic Press, New York).

JAKoBsen, T. (1978 a). Skreiinnsiget i Lofoten i 1976. Fisken Hav., (1), 1-8.

JAKOBSEN, T. (1978 b). Skreiinnsiget i Lofoten i 1977. Fisken Hav., (1), 9-19.

JANGAARD, P. M. (1974). The capelin (Mallotus villosus): biology, distribution, exploitation, utilization, and composition. Dept. of the Environment, Fisheries and Marine Service, Ottawa, Canada.

Jeffers, G. W. (1931). The Life History of the Capelin Mallotus villosus. Ph.D. Thesis, Univ. of Toronto, Ontario, Ca., $86 \mathrm{pp}$.

Johnstone, R., Simpson, T. H., and Youngsson, A. F. (1977). Sex reversal in salmonid culture. Aquaculture, 13 (1978), 115-134.

JONES, R. (1979). Simulation Studies of the Larval Stage and Observations on the First Two Years of Life, w/Particular Reference to the Haddock. ICES/ELH SYMP/M:1. Woods Hole ELH Symposium, April 1979, Mimeo.

JONES, R., and HALL, R. (1973). A simulation model for studying the population dynamics of some fish species. Pp. 35-39 in The Mathematical Theory of the Dynamics of Biological Populations, edited by Partlett and Hiorns (Academic Press, New York), 347 pp.

Kerr, S. R. (1971). A simulation model of lake trout growth. J. Fish. Res. Bd. Canada, 28, 815-819.

Laevastu, T., Favorite, F., and Larkins, H. A. (1979). Resource assessment and evaluation of the dynamics of the fisheries resources in the NE Pacific with numerical ecosystem models. U.S. Dept. Commerce, NOAA, NMFS, North-west and Alaska Fisheries Cenls, Seattle, WA 98112, 35 pp.

Larrick, S. R., Dickson, K. L., Cherry, D. S., and Cains, J., JR. (1978). Determining fish avoidance in polluted waters. Hydrobiologica, 61, 257-265.

LOENG, H. (1979). A review of the sea ice conditions of the Barents Sea and the area west of Spitsbergen. Fisken Hav., (2), 29-75.

LOENG, H. (1981). Distributions of adult capelin in relation to temperature. Fisken Hav., (6), 10-17.

Lund, A. (1981). Food of capelin, Mallotus Villosus (Müller) in the Barents Sea (Ernæring hos lodde, Mallotus villosus (Müller) i Barentshavet. Ph.D. Thesis, Inst. for Fisheries Biology in Bergen, 128 pp. 
MARR, J. C. (1955). The 'critical period' concept in the early life history of marine fishes. Cons. Perm. Inst. Exp. Mer., Journal du Cons., 21, 160-170.

Marshall, S. M., and OrR, A. P. (1972). The biology of a marine copepod (Springer-Verlag, Berlin), 195 pp.

MAtudA, K., and SANnOmya, N. (1980). Computer simulation of fish behavior in relation to fishing gear-I. Bull. Japanese Soc. Scientific Fisheries, 46, 689-699.

Miller, R., and MCINerNeY, M. (1978). Packing Density and Swimming Speed of Schooling Capelin (Mallotus villosus). ICES C.M. 1978/B:26. Fishing Technology Committee.

Milsum, J. H., and Roberge, F. A. (1973). Physiological regulation and control. Pp. 1-96 in Foundations of Mathematical Biology, Vol. III, edited by R. Rosen (Academic Press, N.Y.), 412 pp.

MONSTAD, T. (1971). Alder, vekst og utbredelse av lodde i Barentshavet og ved kysten av Nord-Norge 1968-1970. Thesis (Cand. real), Univ. i Bergen, Norge (mimeo).

Monstad, T., and Kovalyov, S. M. (1973). Capelin investigations in the Barents Sea in November-December 1972. Fiskets Gang, 17, 350-353.

MølleR, D., and OlsEN, S. (1962). Norwegian capelin investigations. ICES Distant North Seas C.M. 1962, No. 34, 10 pp. + figs.

NakKen, O., and Dommasnes, A. (1977). Acoustic estimates of the Barents Sea. Capelin stock 1971-1976. ICES C.M. 1977/H:35; 10 pp.

NovitskiY, V. P. (1961). Permanent Currents of the Northern Barents Sea. Trans. from Russian by U.S. Naval Oceanographic Office, Wash. D.C. 1967.

OLSEN, S. (1968). Some Results of the Norwegian Capelin Investigations 1960-65. ICES Rapp. P.-v. Rena Cons. Perm. Int. Exp. Mer., 158, 18-23.

Ponomorenko, V., Ponomorenko, I., and Yaragina, N. (1978). Consumption of the Barents Sea Capelin by Cod and Haddock in 1975-1976.

Ponomorenko, I. Y., and Yaragina, N. A. (1978). Year to Year and Seasonal Fluctuations in the Feeding of the Barents Sea Cod on Capelin in 1947-1976. ICES Demensal Fish Committee C.M. 1978/G:24.

Privolnev, T. I., Galkina, Z. I., and Galkin, G. G. (1964). Effect of the Size of Their Eggs on the Offspring. Reported in Biological Abstracts, (48); 11215, 1967.

Prokhorov, V. S. (1968). Materials on the ecology of capelin in the Barents Sea. Rapp. P.-v. Reun. Cons. Peim. Inst. Exp. Merk., 158, 23-31, 1965.

Proknorov, V. S. (1965). Ecology of the Barents Sea capelin (Mallotus Villosus) and the Prospect of its Industrial Utilization. Translated by Foreign Languages Division, Fisheries Research Board of Canada, St. John's, Newfoundland, 1967, Transaction Series No. 813.

Prokhorov, V. S. (1960). Post-spawning survival of the Barents Sea capelin. ICES C.M. 1960 , no. 165.

Reed, M., Spaulding, M. L., and Cornillon, P. (1981). A fishery-oilspill interaction model: simulated consequences of a blowout, pp. 99-114 in Applied Operations Research in Fishing, edited by K. B. Haley (Plenum Press, N.Y.), 490 p.

Reed, M., Spaulding, M. L., and CoRnillon, P. (1980). An oilspill-fishery interaction model: formulation and applications. U. Rhode Island, Dept. Ocean Engineering, Kingston, RI, USA 02879, 220 pp.

RøRVıк, C. J. (1981). Simulations of the northeast Atlantic stock of minke whales. Bergen, Inst. Marine Research SC/32/Mi. 8., 18 pp.

RøRVIK, C. J., and Christensen, I. (1980). Considerations of factors affecting the use of catch per unit effort in the Norwegian minke fishery for stock estimates. Inst. Marine Research, Bergen Sc/32/Mi. 9, 14 pp.

SANnOmiYA, N., and MAtudA, K. (1981). Modeling of fish behavior in relation to fishing. 25 pp., paper submitted (presented) at the IFAC VIIIth World Congress.

SÆTRE, R., and GJøSÆTER, J. (1975). Ecological Investigations on the spawning grounds of the Barents Sea capelin. Fiskeri Direktorat Skriv. Undersøk,16, 203-227.

Shulga, A. D., and Belusov, V. V. (1976). Dependence of certain biological characteristics of the Barents Sea capelin on the temperature regime. ICES, Pelagic Fish (Northern) Committee C.M. 1976/H:5.

SlaGsTAD, D. (1980). Modeling and simulation of physiology and population dynamics of copepods, effects of physical and biological parameters, Norwegian Technical University, Division of Engineering Cybernetics, Ph.d. Thesis, 179 pp. 
Stepanov, A. S., Churmasov, A. V., and Cherkashin, S. (1979). Migration Direction Finding by Chum Salmon According to the Sun. Soviet Journat of Marine Biology, 5, 92-99.

StotT, B., and Buckley, B. R. (1979). Avoidance experiments with shoals of minnows (Phoxinus phoxinus) in a laboratory stream channel. J. Fish. Biol., 14, 135-146.

VILHJÁlmSON, H. (1974). Ransøknir á lodnusýnum in afla veidi- og ransøknaskipa a timabilinu jánuar-april 1974. Lo uveidanar, 1974, Reykjavik. (Reported by Friðgeirsson, 1976.)

VILHJALMSON, H. (1968). A contribution to the knowledge of the Icelandic capelin. ICES Rapp. Reun. Cons. Perm. exp. Mer, 158, 32-38.

Webs, P. W. (1977). Effects of size on performance and energetics of fish. In Scale Effects in Animal Locomotion (Academic Press, London), edited by J. T. Pedley, pp. 315-331.

WeBB, P. W. (1975). Hydrodynamics and energetics of fish propulsion. Dept. of the Envmnt, Fisheries and Marine Center, Ottawa, Canada, 159 pp.

WeIHS, D. (1973). Hydrodynamics of fish schooling. Nature, 241, 290-291. Optimal cruising speed for migrating fish; ibid., 245, 48-50.

WiborG, K. F. (1954). Investigations on zooplankton on coastal and offshore waters of western and northwestern Norway, with special reference to copepods. Fiskeridirektoratets Skrifter Ser. Havunders., XI (1).

WINTERS, G., and CASCADDEN, J. (1978). Review of capelin ecology and estimation of surplus yield from predator dynamics. ICNAF Res. Bull., 13, 21-29.

ZenkeVITCH, L. (1963). Biology of the Seas of the U.S.S.R. (Academic Press, London), 931 pp. 